\title{
Impact of circulating tumor DNA in hepatocellular and pancreatic carcinomas
}

\author{
Sameer A. Dhayat ${ }^{1} \cdot$ Zixuan Yang $^{1}$
}

Received: 23 January 2020 / Accepted: 15 April 2020 / Published online: 27 April 2020

(c) The Author(s) 2020

\begin{abstract}
Hepatocellular carcinoma (HCC) and pancreatic cancer (PC) belong to the most lethal malignancies worldwide. Despite advances in surgical techniques and perioperative multidisciplinary management, the prognosis of both carcinoma entities remains poor mainly because of rapid tumor progression and early dissemination with diagnosis in advanced tumor stages with poor sensitivity to current therapy regimens. Both highly heterogeneous visceral carcinomas exhibit unique somatic alterations, but share common driver genes and mutations as well. Recently, circulating tumor DNA (ctDNA) could be identified as a liquid biopsy tool with huge potential as non-invasive biomarker in early diagnosis and prognosis. CtDNA released from necrotic or apoptotic cells of primary tumors, metastasis, and circulating tumor cells can reveal genetic and epigenetic alterations with tumor-specific and individual mutation and methylation profiles. In this article, we focus on clinical impact of ctDNA as potential biomarker in patients with HCC and PC.
\end{abstract}

Keywords Hepatocellular carcinoma $\cdot$ Pancreatic cancer $\cdot$ Circulating tumor DNA $\cdot$ Next-generation sequencing $\cdot$ Digital droplet PCR

\begin{tabular}{ll}
\multicolumn{2}{l}{ Abbreviations } \\
ADAMTS1 & $\begin{array}{l}\text { A disintegrin and metalloproteinase with } \\
\text { thrombospondin motifs 1 }\end{array}$ \\
AFP & $\begin{array}{l}\text { Alpha-fetoprotein } \\
\text { APC }\end{array}$ \\
Adenomatous polyposis coli \\
ARID1A & AT-rich interaction domain 1A \\
BNC1 & Basonuclin-1 \\
BRCA & Breast cancer gene \\
CA & Carbohydrate antigen \\
CCND1 & Cyclin D1 \\
CDKN2A & Cyclin-dependent kinase inhibitor 2A \\
CEA & Carcinoembryonic antigen \\
Cf & Cell-free \\
Ct & Circulating tumor \\
CTNNB1 & Catenin Beta 1 \\
ddPCR & Digital droplet PCR
\end{tabular}

Sameer A. Dhayat

sameer.dhayat@ukmuenster.de

Zixuan Yang

yzxbcchina@uni-muenster.de

1 Department of General, Visceral and Transplantation Surgery, University Hospital Muenster,

Albert-Schweitzer-Campus 1 (W1), 48149 Munster,

Germany

$\begin{array}{ll}\text { DFS } & \text { Disease-free survival } \\ \text { EGFR } & \text { Epidermal growth factor receptor } \\ \text { 5-FU } & \text { 5-Fluorouracil } \\ \text { GSTP1 } & \text { Glutathione S-transferase P 1 } \\ \text { HBV } & \text { Hepatitis B virus } \\ \text { HCC } & \text { Hepatocellular carcinoma } \\ \text { HCV } & \text { Hepatitis C virus } \\ \text { KRAS } & \text { Kirsten rat sarcoma viral oncogene homolog } \\ \text { LINE-1 } & \text { Long interspersed nucleotide element 1 } \\ \text { MSP } & \text { Methylation-specific PCR } \\ \text { NGS } & \text { Next-generation sequencing } \\ \text { PC } & \text { Pancreatic cancer } \\ \text { PDGFR } & \text { Platelet-derived growth factor receptor } \\ \text { qRT } & \text { Quantitative real time } \\ \text { RASSF1A } & \text { Ras association domain family protein 1A } \\ \text { RFS } & \text { Recurrence-free survival } \\ \text { SFRP1 } & \text { Secreted frizzled-related protein 1 } \\ \text { TERT } & \text { Telomerase reverse transcriptase } \\ \text { TGF } & \text { Transforming growth factor } \\ \text { VEGFR } & \text { Vascular endothelial growth factor receptor } \\ \text { WNT } & \text { Wingless-type } \\ & \end{array}$




\section{Background}

Hepatocellular carcinoma (HCC) and pancreatic cancer (PC) represent two of the most challenging visceral malignancies in oncology with rising incidence and lack of reliable biomarkers for early diagnosis, prognosis, and therapy response. PC and HCC are estimated to become the second and third respective leading causes of cancerrelated death in western countries by 2030 (Rahib et al. 2014; Siegel et al. 2019). As both carcinoma entities share some common risk factors, either environmental or genetic, combined analyses may provide useful information. Hepatocellular carcinogenesis is a multistep process occurring in one-third of patients with liver cirrhosis, on the background of chronic infection with hepatitis $\mathrm{B}$ or $\mathrm{C}$ virus (HBV, HCV), alcoholic or non-alcoholic steatohepatitis, and obesity (Villanueva 2019). PC occurs with increased frequency among individuals with tobacco smoking, type 2 diabetes, obesity, chronic pancreatitis or hereditary risk factors (Ryan et al. 2014). In both carcinoma entities, the majority of patients are diagnosed at advanced stages with a low 5-year survival rate of less than $10-20 \%$ and a high 5-year recurrence rate of 70-80\%, even following oncological tumor resection (Siegel et al. 2019). Therefore, early diagnosis at surgically manageable stages and early recurrence detection would have a tremendous impact on survival of patients with HCC or PC. However, current screening of proteomic serum markers, such as alpha-fetoprotein (AFP) in HCC or carcinoembryonic antigen (CEA) and carbohydrate antigen (CA) 19.9 in PC have not shown to be effective due to their reduced predictive values (Bolondi et al. 2013; Gamil et al. 2018; Poruk et al. 2013). In addition, imaging techniques failed to detect early lesions or to distinguish between benign and malignant lesions, so far. In addition to the risk of neoplastic needle tract seeding, minimal invasive solid biopsies by endoscopic-ultrasound-guided fine needle aspiration in PC or percutaneous needle biopsy in HCC cannot accurately track dynamic changes due to high tumor heterogeneity (Stigliano and Burroughs 2005; Yoshida et al. 2019). This molecular heterogeneity is the reason for the large variation in individual patient $s$ prognosis and response to chemotherapy.

Cytotoxic chemotherapy agents continue to form the backbone for the treatment of advanced PC limited to the pyrimidine antimetabolites gemcitabine and 5-fluorouracil (5-FU), Topoisomerase I inhibition by irinotecan, the DNA crosslinking agents oxaliplatin and cisplatin, and the tubulin inhibitor paclitaxel (Burris et al. 1997; Reni et al. 2005; Stathopoulos et al. 2006). However, the median survival remains $6-11$ months. Since 2007 , gemcitabinebased combination chemotherapies with the selective epidermal growth factor receptor (EGFR) tyrosine kinase inhibitor erlotinib could improve the overall survival in locally advanced, unresectable, or metastatic PC (Moore et al. 2007). 5-FU-based FOLFIRINOX therapy including calcium folinate, irinotecan, and oxaliplatin since 2011 as well as the addition of nanoparticle albumin-bound paclitaxel to gemcitabine since 2013 significantly prolonged the overall survival and progression-free survival compared with mono-gemcitabine therapy in locally advanced and metastatic PC (Conroy et al. 2011; Von Hoff et al. 2013). Due to its greater toxicity, FOLFIRINOX was recommended for PC patients in good physical condition. High resistance to current chemotherapy regimens still affects the treatment of PC and HCC (Chin et al. 2018). However, better therapy response with extended survival time of more than 2 years in small subgroups of patients with advanced PC seems to be connected with exceptionally favorable prognostic factors and molecular characteristics (Collisson et al. 2011; Cui et al. 2012).

Despite the identification of many frequently mutated genes as potential therapeutic targets in HCC, the multikinase inhibitor Sorafenib that inhibits vascular endothelial growth factor receptor (VEGFR) 1-3, platelet-derived growth factor receptor (PDGFR) beta, c-KIT, and RAF/ mitogen-activated protein/MEK was the sole drug approved for the treatment of advanced HCC between 2007 and 2016 with a response rate of less than $5 \%$ and an extended median overall survival of 2.5 months (Llovet et al. 2008). Currently, two first-line alternatives to Sorafenib are approved. The first Lenvatinib is a multikinase inhibitor as well, that inhibits VEGFR 1-3, PDGFR alpha, fibroblast growth factor receptor 1-4, c-Kit proto-oncogene receptor tyrosine kinase, and RET proto-oncogene with an improved median overall survival of 13.6 months versus 12.3 months. The other one is the monoclonal antibody Nivolumab, that inhibits the immune checkpoint molecule programmed cell death protein 1 and showed a response rate of $23 \%$ in Sorafenib naïve HCC patients (Forner et al. 2018). Therefore, the most effective treatment of heterogeneous cancers like HCC and PC might be a tailored combination of drugs targeting specific genomic and epigenomic alterations. Routine molecular testing is still performed in clinical diagnostic for targeted therapy and prognostic stratification in cancer entities, such as breast cancer, melanoma and leukemia (El-Deiry et al. 2019). In patients with diagnosed colorectal carcinoma, the decision for an anti-EGFR antibody therapy is based on routine mutation analysis of kirsten rat sarcoma viral oncogene homolog (KRAS), neuroblastoma RAS viral oncogene homolog, and B-Raf proto-oncogene serine/threonine kinase gene resulting in a valine-to-glutamate change at the residue 600 (Karapetis et al. 2008). In addition to environmental factors, recent genome-wide association studies revealed that genetic and epigenetic abnormalities might be significant 
determinants of HCC or PC susceptibility with important influence on the individual predisposition to disease progression, e.g. chronic inflammation, and resulting carcinogenesis. Moreover, several recent studies have shown that identification of molecular biomarkers and real-time monitoring of disease and therapy efficacy in PC and HCC could be achieved by liquid biopsies (Tables 1 and 2). In this review, we discuss recent studies focusing on detection and clinical impact of circulating DNA mutation and methylation as potential biomarker for early diagnosis, prognosis, and therapy response in HCC and PC.

\section{Cell-free and circulating tumor DNA}

Cell-free (cf) DNA originates from normal cells exported by exosomes as well as from apoptotic and necrotic cells with highly fragmented, double-stranded DNA of approximately 150-180 base pair fragments in size being released into the bloodstream. In 1948, Mandel and Metais first reported the presence of cfDNA in human circulation followed by detection in urine, saliva, and other body fluids (Botezatu et al. 2000; Liao et al. 2000; Mandel and Metais 1948; Mao et al. 1994). A recent study showed that most of cfDNA derive from bone-marrow and liver in healthy individuals (Sun et al. 2015). Examples for clinical applications of cfDNA are the non-invasive prenatal testing for chromosomal aneuploidies by fetal cfDNA in the plasma of pregnant women or the monitoring of graft rejection following organ transplantation by donor-derived cfDNA in the plasma of the recipients (Chiu et al. 2008; Lo et al. 1997, 1998; Snyder et al. 2011). In 1977, Leon et al. demonstrated that cancer patients had a relative higher level of cfDNA than healthy controls with increased levels after radiation therapy (Leon et al. 1977). It was postulated that cancer patients have higher levels of cfDNA than healthy individuals (Shapiro et al. 1983). However, cfDNA levels have also been linked to outcomes in patients with a variety of other physiological and pathological conditions, including exercise, inflammation, circadian rhythm, exposure to smoking, sepsis, and trauma (Aucamp et al. 2018). In fact, cfDNA is composed of both coding and non-coding genomic DNA that can be used to examine mutations and polymorphisms, microsatellite instability, and epigenetic methylation (Bruhn et al. 2000; Downward 2003; Grutzmann et al. 2008; Jahr et al. 2001; Schwarzenbach et al. 2011). Epigenetic changes are considered as an early event in carcinogenesis and might, therefore, be a suitable early diagnostic tumor marker.

Since the extraction of plasma DNA with the same genetic changes as the primary tumor in 1989 and identification of mutated KRAS sequences in the plasma or serum from patients with PC in 1994, circulating tumor (ct) DNA is becoming a research hotspot with high potential as liquid biopsy marker in cancer medicine (Sorenson et al. 1994; Stroun et al. 1989). CtDNAs as a part of circulating cfDNA are mutant DNA fragments released to the circulation by tumor cells of different cancer entities. CtDNA is considered to be released from an increasing proportion of necrotic and apoptotic cells in primary tumors, secondary deposits and circulating tumor cells, corresponding to an increase in ctDNA. The half-lives of ctDNAs range from $15 \mathrm{~min}$ to a few hours which enables ctDNA analysis to be considered as a 'real-time' snapshot of disease burden with supposed clearance through nuclease activity, renal excretion, and uptake by the liver and spleen (Diehl et al. 2008; Minchin et al. 2001; Tamkovich et al. 2006; Yu et al. 2013). CtDNA can be detected by tumor-specific mutants and are less impacted by intratumor heterogeneity than a single specimen of tumor tissue (Bettegowda et al. 2014; Diaz and Bardelli 2014; Fleischhacker and Schmidt 2007; Melo et al. 2015; Sausen et al. 2014). It is supposed, that ctDNA harbor the same (epi-) genetic alterations as the originating primary tumor cells. Recently, Heitzer et al. demonstrated the impact of ctDNA in early detection, surveillance, and personalized treatment in different cancer entities like colorectal, breast, and non-small cell lung cancer (Heitzer et al. 2015). In addition, previous studies have indicated a positive correlation between ctDNA levels and tumor burden in various cancer types with increasing copy numbers of ctDNA per $\mathrm{mL}$ plasma in advanced and metastatic tumors, as well as different methylation status of ctDNA to normal cfDNA and blood leukocytes (Bettegowda et al. 2014; Guo et al. 2017; Madic et al. 2012; Xu et al. 2017). Furthermore, it is hypothesized that ctDNA could be a signaling trigger for cancer progression by horizontal DNA transfer affecting the biology of host cells (Bergsmedh et al. 2001; Gahan and Stroun 2010; Garcia-Olmo et al. 1999). Thus, ctDNA levels may serve as an early biomarker for diagnostic and therapy monitoring, prior to clinically or radiographically measureable changes of tumor burden in patients. However, ctDNAs represent a variable fraction of cfDNAs ranging from $0.01 \%$ to more than 50\% in cancer patients (Diaz and Bardelli 2014; Diehl et al. 2008). Deoxyribonuclease activity and the release of cfDNA by normal cells in peripheral circulation reduces ctDNA concentrations. Therefore, the detection of ctDNA is challenging and necessitates the standardization of extraction procedures to be able to distinguish ctDNA from the large amount of cfDNA.

\section{Next-generation sequencing and digital droplet PCR}

In the last 2 decades, growing knowledge on non-coding genome functionality and genome-wide sequence variation has improved personalized medicine and molecular 


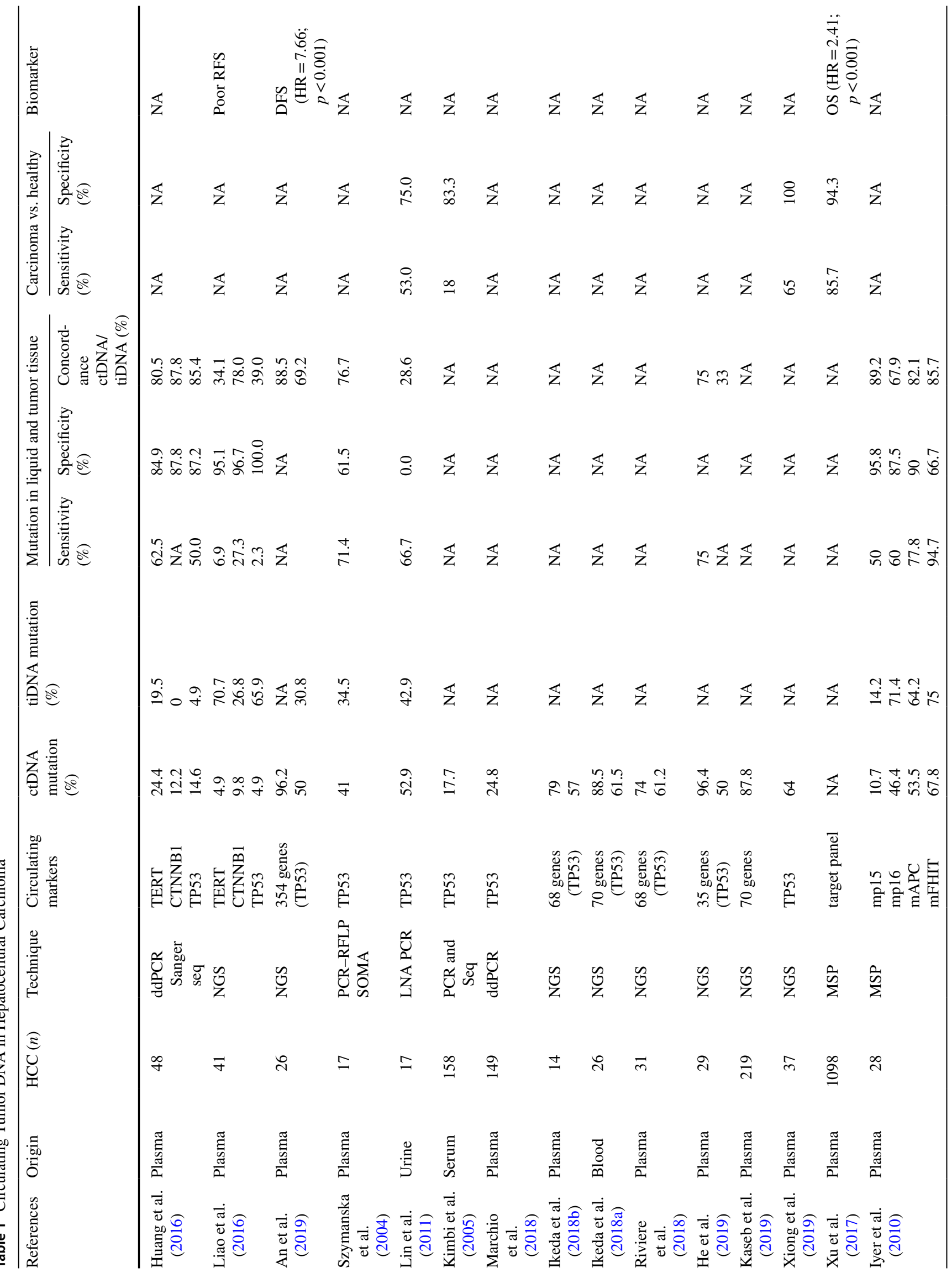




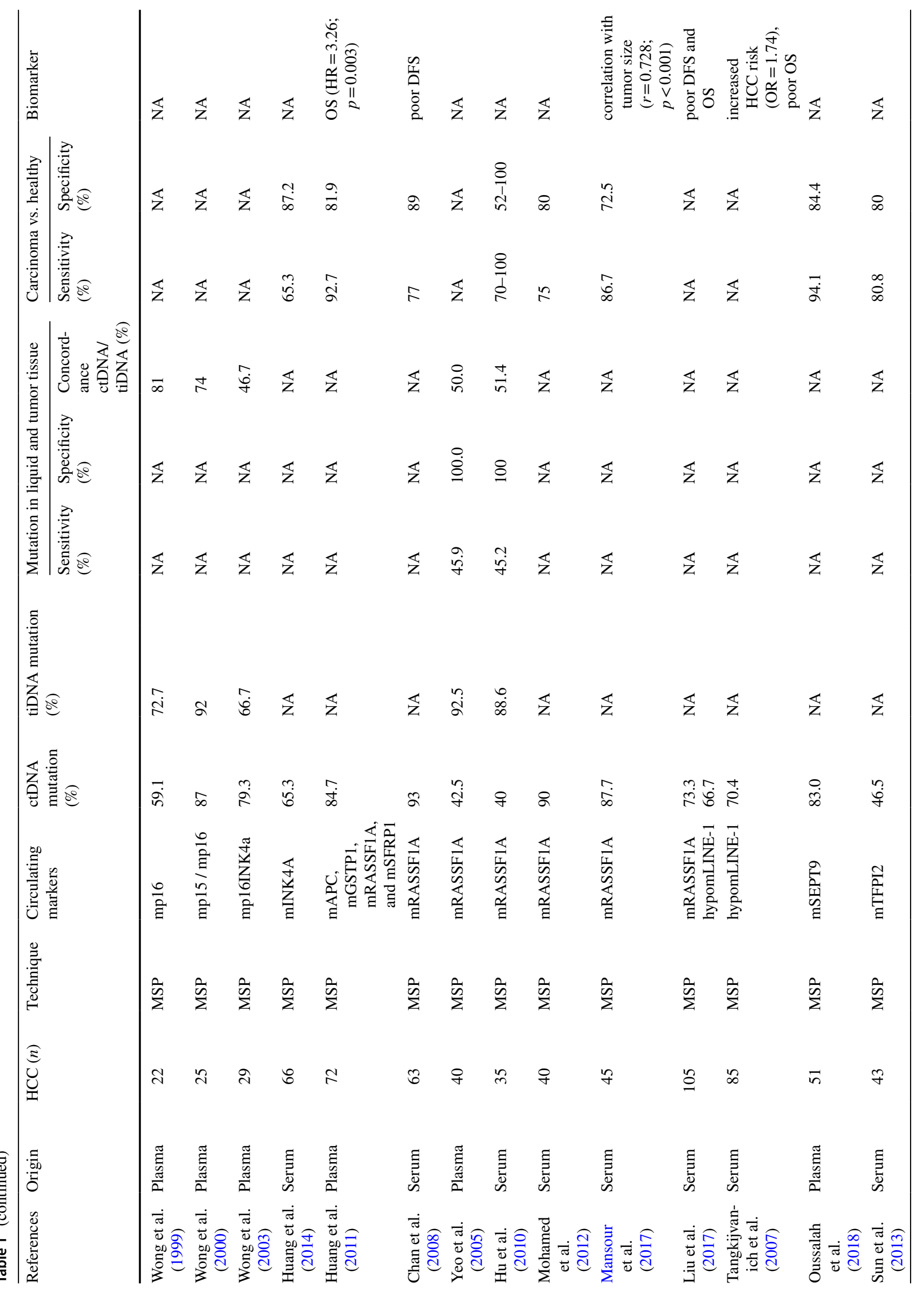




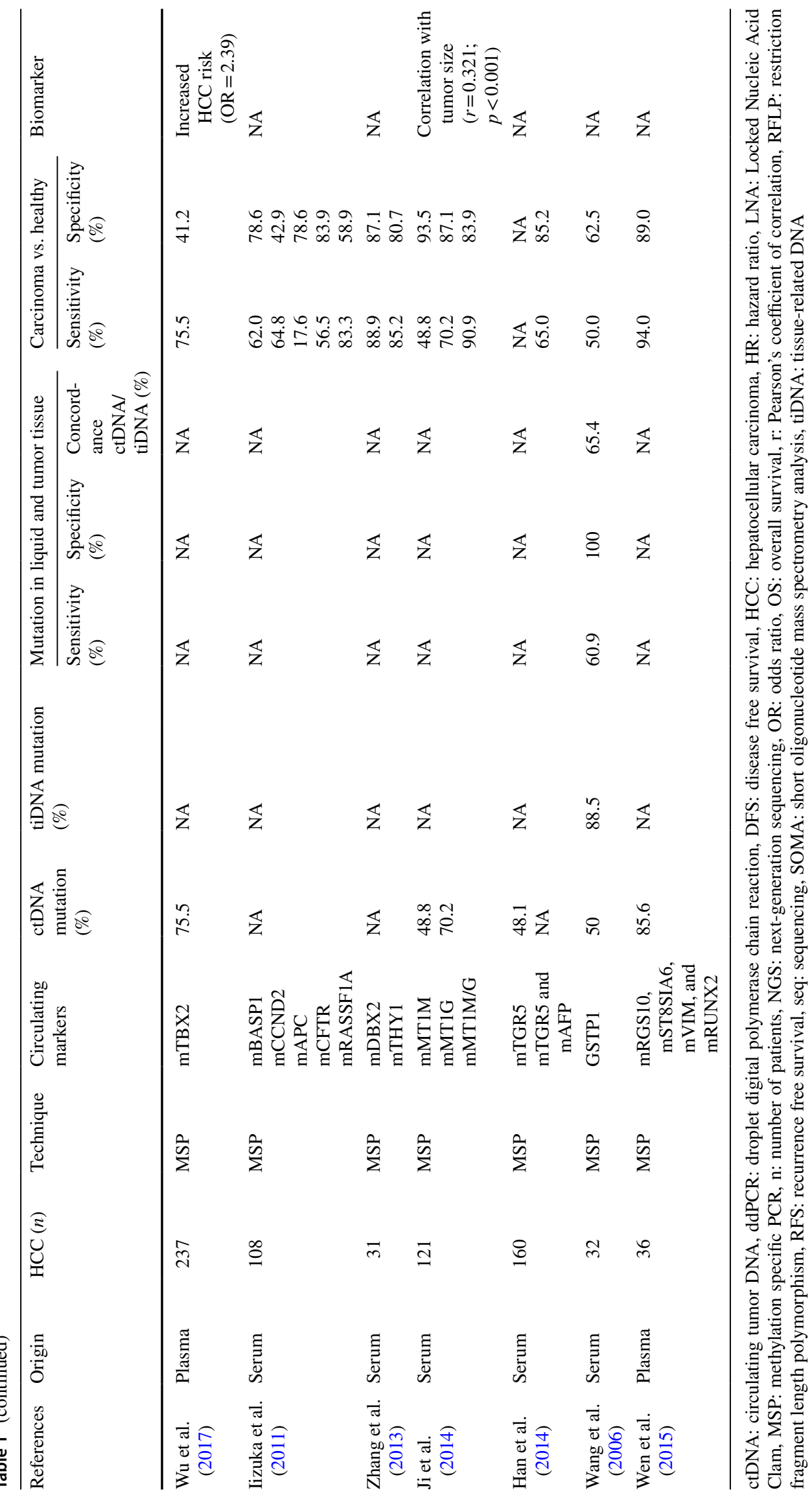




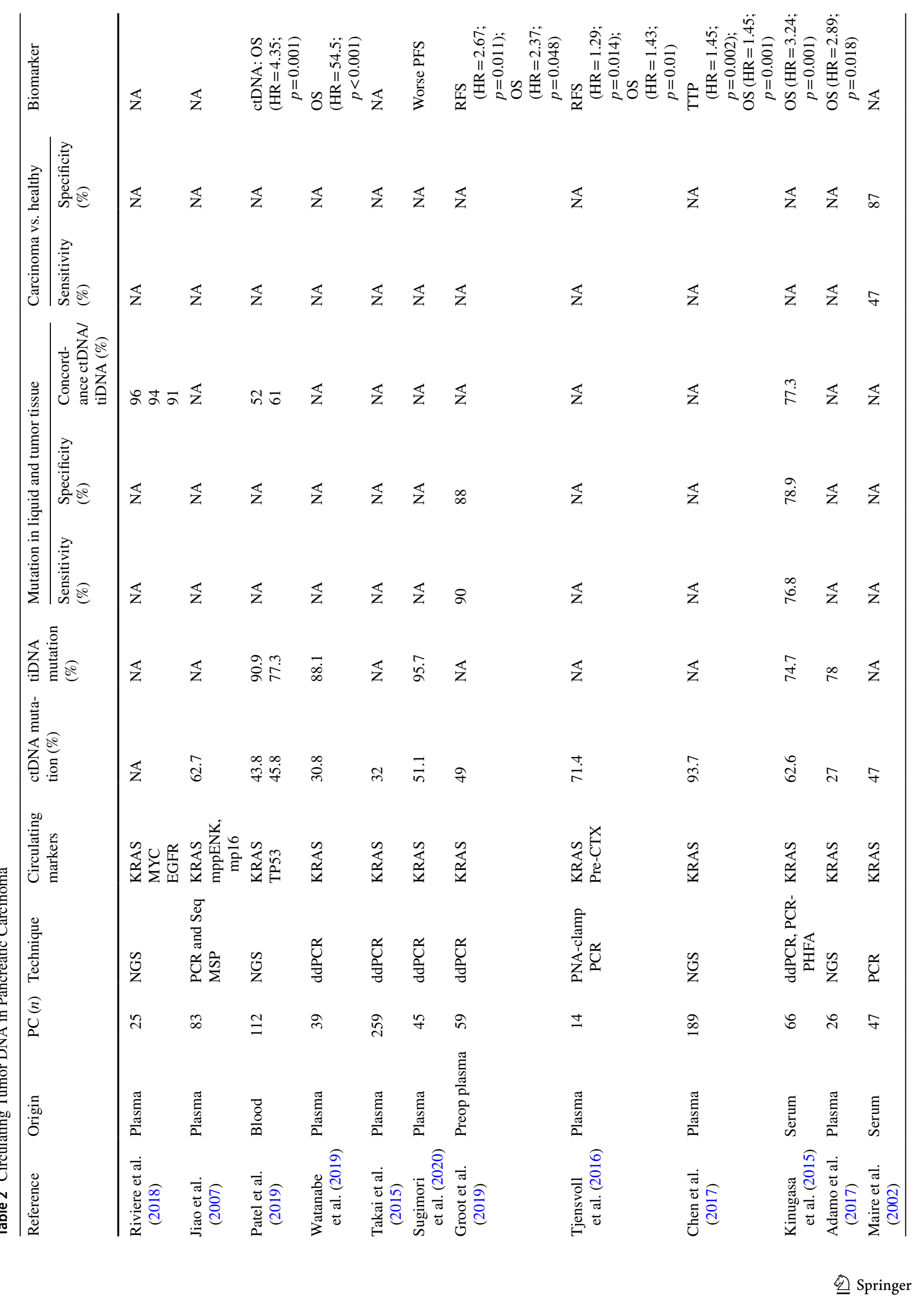




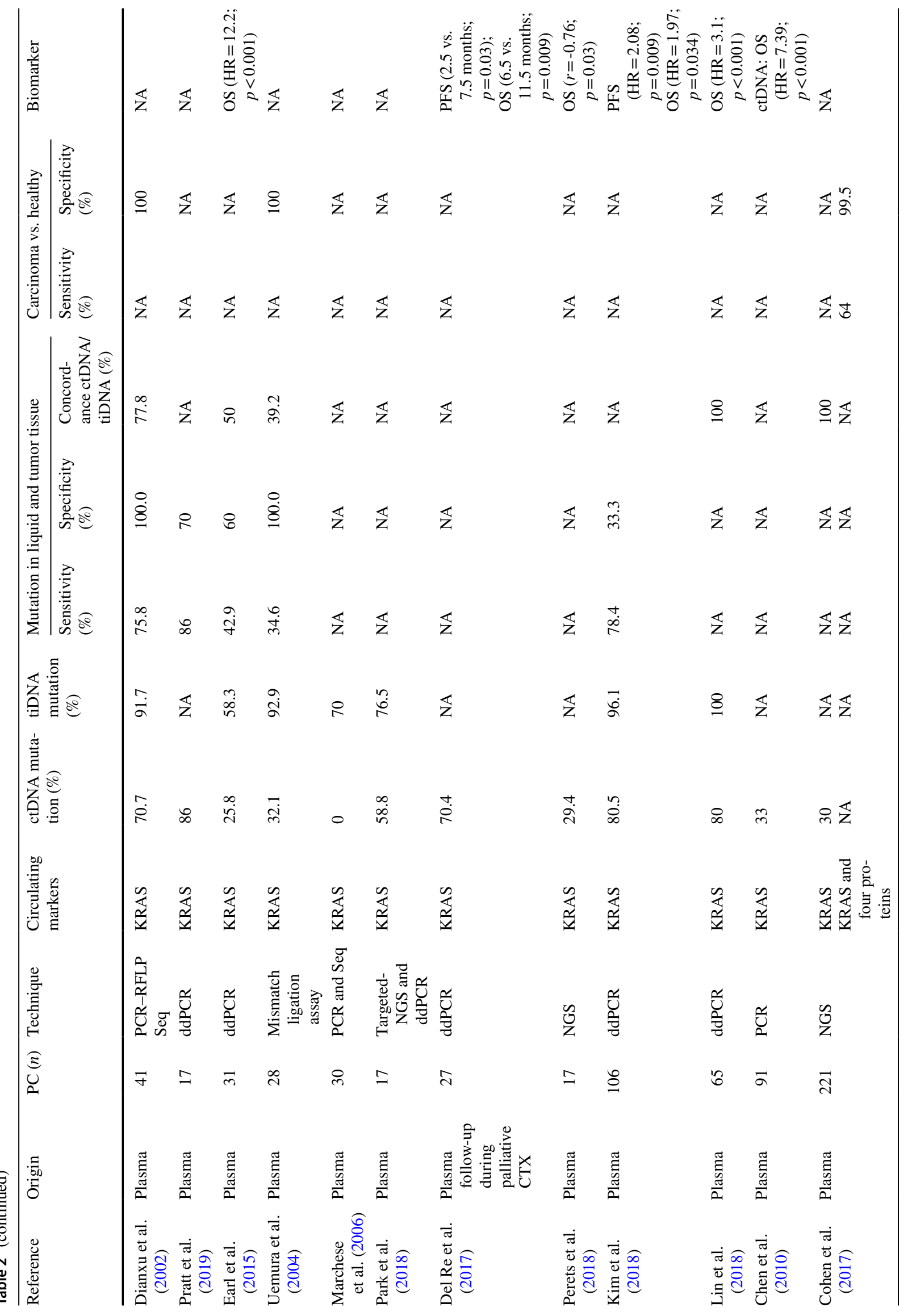




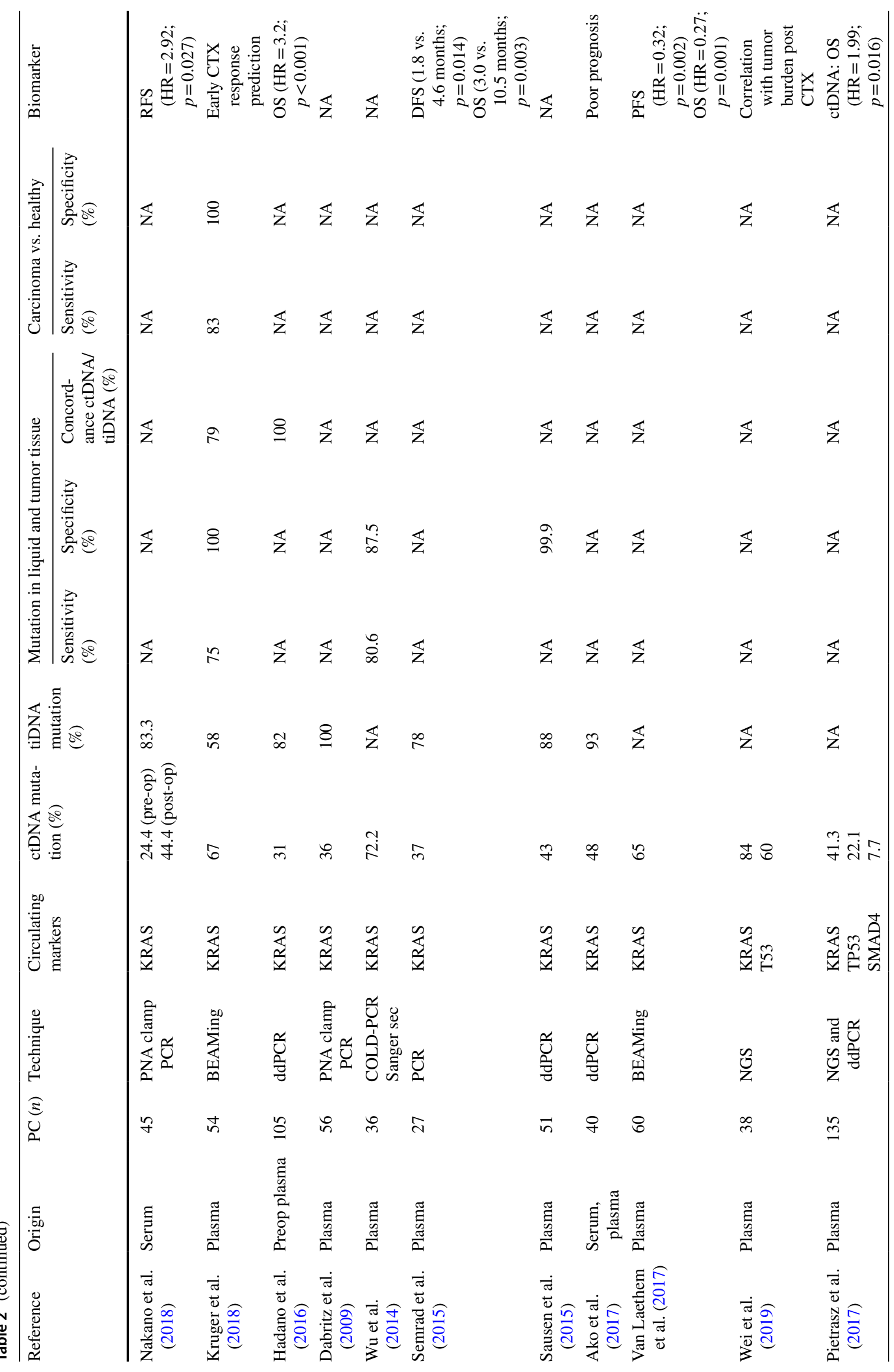




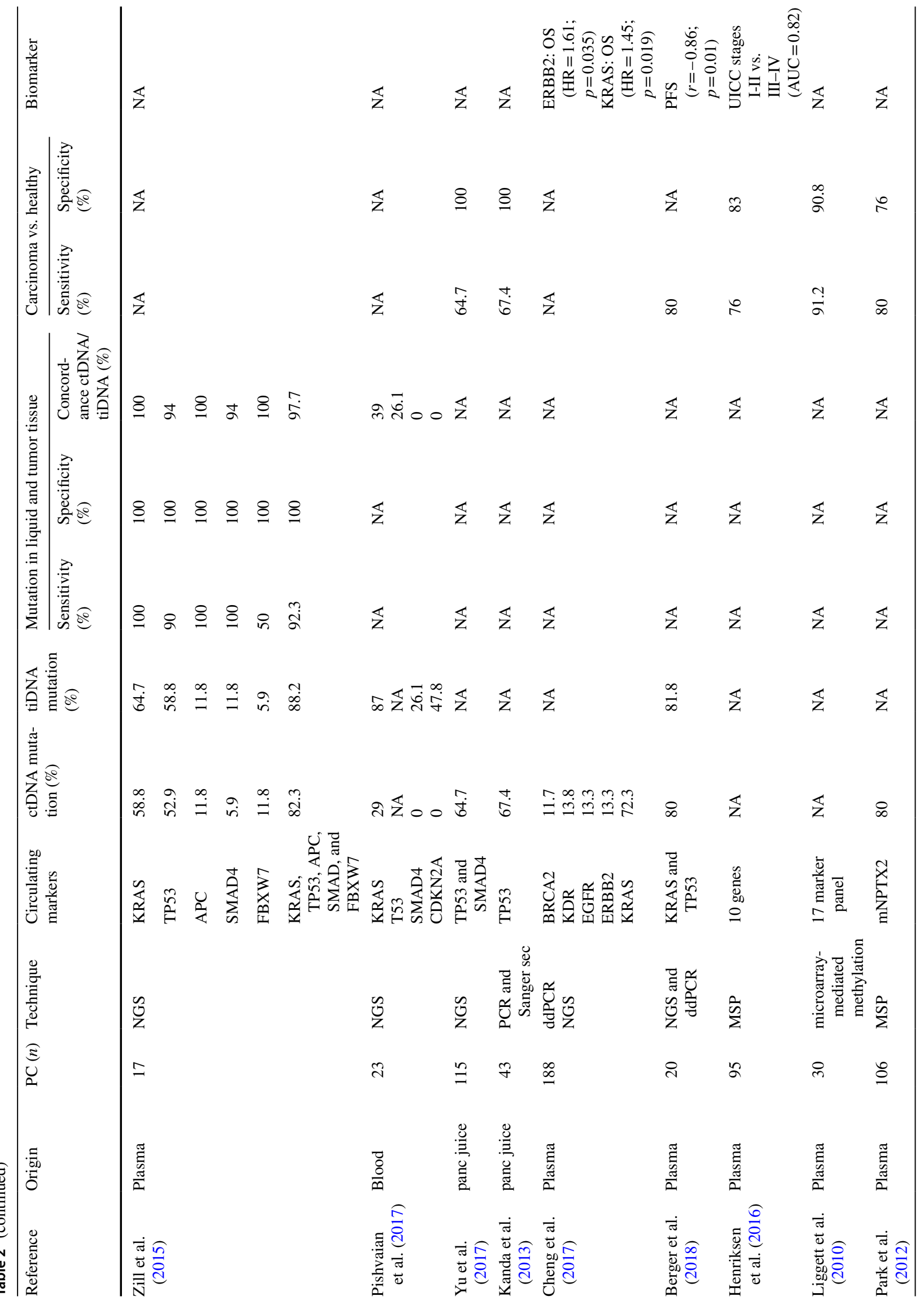




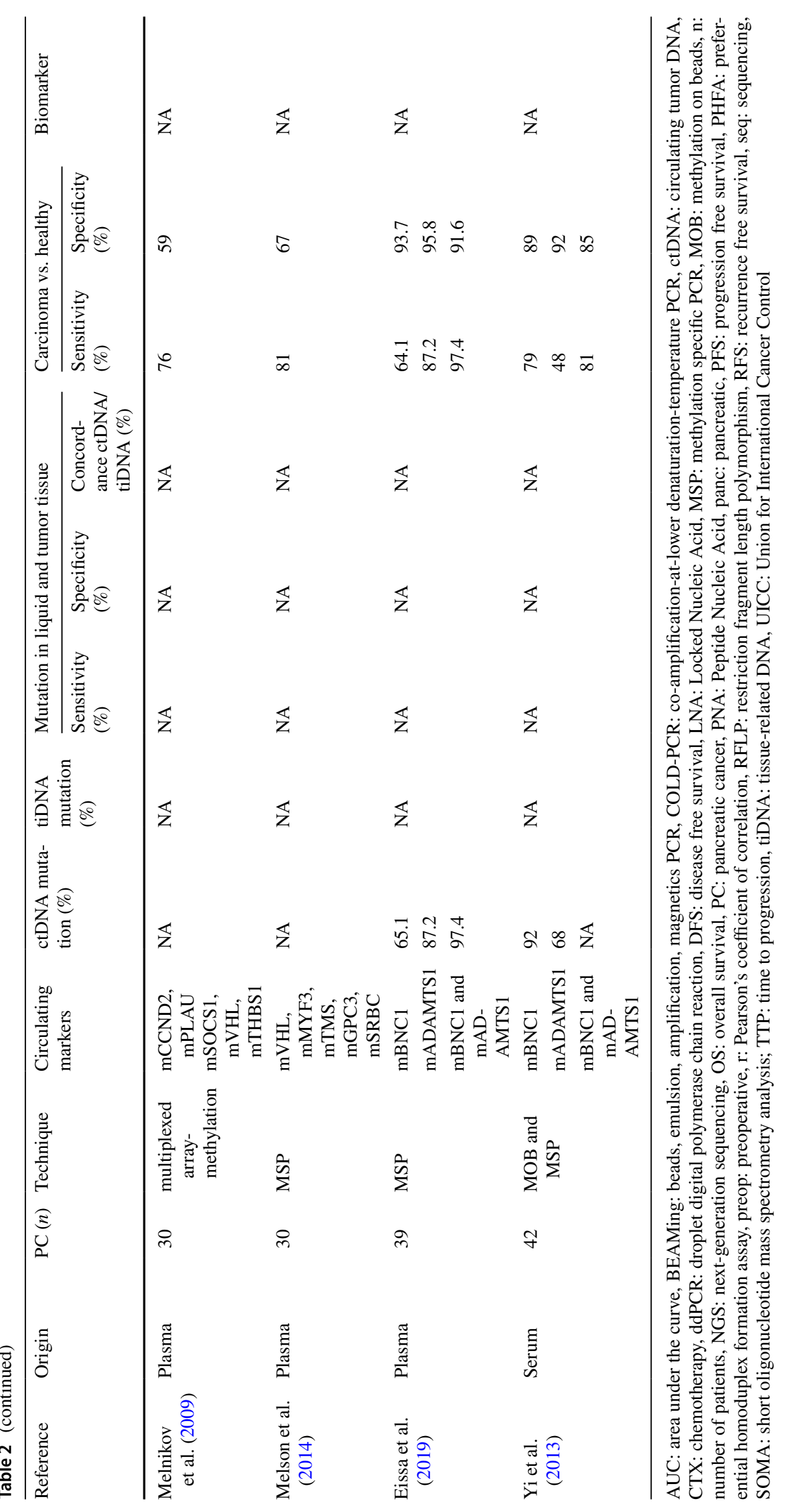


oncology. With technological advances broadly categorized into PCR-based and genomic sequencing-based techniques, sensitivity and specificity of biomolecular techniques for ctDNA detection have been highly improved. Currently, high-throughput next-generation sequencing (NGS) and digital droplet PCR (ddPCR) are the most promising methods for the detection of mutations in liquid biopsies. In general, plasma samples are used in preference over serum because of lower concentrations of wild-type DNA (Jung et al. 2003). NGS techniques allow the simultaneous assessment and detection of multiple genetic aberrations and copy number changes, including targeted techniques such as enhanced tagged amplicon deep sequencing, or wholeexome sequencing. The aim of NGS is to generate extensive information about the mutation landscape, then to screen the genome and discover new genomic aberrations, e.g. those that confer resistance to a specific targeted therapy (Murtaza et al. 2013). The whole-genome and whole-exome sequencing could provide more comprehensive information regarding the mutant status of ctDNA. However, the targeted region deep sequencing, which focuses on a fewer gene loci with ultra-deep sequencing, has gained popularity, because the sequencing region can be customized according to cancer types, sequencing purpose, costs, and turnaround time (Leary et al. 2010; Martinez et al. 2013). Among PCR-based techniques, digital PCR including droplet PCR and BEAMing (beads, emulsion, amplification, magnetics) PCR appears as the most promising approach for detection of highly recurrent hotspot mutations at frequencies as low as $0.01 \%$. Compared to quantitative real-time (qRT) PCR, samples are processed with a water-oil emulsion to allow for individual droplets to be assessed as a discrete PCR sample and does not rely on external calibrant. DNA templates are distributed into thousands of droplets each containing only one DNA fragment. Digital PCR has a higher tolerance for enzyme-inhibiting substances thereby improving sensitivity and specificity of mutant DNA detection (Hindson et al. 2011; Zhang et al. 2015). In combination with circulating nucleic acids, ddPCR has gained wide applicability in liquid biopsy diagnostic of cancer, especially in the assessment of methylation status to identify epigenetic dysregulation during carcinogenesis and measurement of changes in gene expression to early diagnosis of cancer, the absolute quantification of copy number variations to predict disease progression, or the detection of rare mutations within ctDNA to guide targeted therapy (Huggett et al. 2015).

\section{Genomic alterations of ctDNA in HCC}

NGS profiling of surgically resected HCC revealed a highly heterogeneous cancer caused by the accumulation of genomic and epigenomic alterations (Ozen et al. 2013).
Recently, integrative genomic characterization by whole exome sequencing and analyses of DNA copy number, DNA methylation, RNA, microRNA, and proteomic expression defined two major molecular subtypes of HCC. One subtype is defined as a proliferation class associated with higher HBV prevalence and poor clinical outcome characterized by activation of proliferative signaling pathways such as Phosphatidylinositide-3-kinase/AKT/mammalian target of rapamycin and RAS- Mitogen-Activated Protein Kinase pathways, Wingless-type (WNT)/Transforming Growth Factor (TGF) beta signaling, amplification of mitogenic Fibroblast Growth Factor family members and of the cell cycle regulatory subunit Cyclin D1 (CCND1) and inactivation of the tumor suppressor TP53. The second subtype contains a heterogenous non-proliferation class associated with higher HCV prevalence or alcohol abuse and a better clinical outcome characterized by WNT-beta-catenin pathway activation via Catenin Beta 1 (CTNNB1) mutation, Telomerase Reverse Transcriptase (TERT) promotor mutation and silencing of the tumor suppressor Cyclin Dependent Kinase Inhibitor 2A (CDKN2A) by mutation and DNA methylation (Comprehensive and Integrative Genomic Characterization of Hepatocellular Carcinoma 2017). This comprehensive and integrative characterization of molecular profiling in HCC tissues followed by the identification and quantification of corresponding ctDNA in the plasma may provide powerful data for targeted therapies and monitoring of therapy response.

Several genomic and epigenomic alterations within ctDNA as molecular targets in the context of aberrant signaling pathways were detected by NGS, ddPCR and methylation-specific PCR (MSP) in HCC patients (Table 1). TERT promotor mutations were found to be the most common point mutations in several carcinoma entities with reactivation of telomerase enabling limitless cell proliferation driven by oncogenes (Bell et al. 2016). In HCC, TERT promotor mutations were found in dysplastic nodules and early stages with a reported frequency of 59-90\% correlating with poor survival (Nault and Villanueva 2015). DdPCR by Huang et al. and NGS by Liao et al. of TERT mutation (c.1-124C $>\mathrm{T}$ ) in plasma ctDNA of $\mathrm{HCC}$ patients revealed a frequency of $23 \%$ and $5 \%$ with a high specificity of $85 \%$ and $95 \%$, respectively (Huang et al. 2016; Liao et al. 2016). Aberrant amplification of TERT was reported to be significantly associated with CTNNB1 mutations in HCC, indicating that the interaction between upregulation of TERT mutations and dysregulation of the WNT-beta-catenin pathway could promote hepatocellular carcinogenesis (Nault et al. 2013). Gain of function mutations in the CTNNB1 gene encoding beta catenin allow the accumulation of beta catenin within the cell nucleus through WNT pathway und promote tumor progression in about $30 \%$ of cases in HCC. CtDNA analysis on CTNNB1 mutations (c.121A > G, c.122C > T, c.133T > C, c134C > T) 
resulted in a high specific frequency of about $10 \%$ in two small HCC collectives screened by ddPCR and NGS (Huang et al. 2016; Liao et al. 2016). Another well known driver gene of HCC is TP53 with a high mutation frequency of more than $30 \%$. Mainly missense mutations in the DNAbinding domain of TP53 are generally thought to abrogate the tumor suppressor function of p53 as the guardian of the genome. Loss of p53 function with consecutive dysregulation of apoptosis, cell cycle arrest, DNA repair and metabolic regulation is a prerequisite for tumor initiation and progression in a multitude of human cancers. However, mutant p53 not only lose tumor suppressive functions of wild-type p53 but also gain new oncogenic properties promoting tumor cell proliferation, angiogenesis, and metastasis. The mechanism for the accumulation of mutant p53 and its mutational gain of function in tumors is not yet well understood. The frequency of mutant TP53 in blood and urine ctDNA of HCC studies ranged between 5 and 60\% (An et al. 2019; He et al. 2019; Huang et al. 2016; Ikeda et al. 2018a, b; Kaseb et al. 2019; Kimbi et al. 2005; Liao et al. 2016; Lin et al. 2011; Marchio et al. 2018; Riviere et al. 2018; Szymanska et al. 2004; Xiong et al. 2019). Liao et al. could reveal that the median recurrence-free survival (RFS) of patients with the presence of TERT, CTNNB1 and TP53 mutations detected in ctDNA post surgical treatment was significantly decreased with 3 versus 12 months (Liao et al. 2016). Similarly, postoperative detection of ctDNA related mutations by An et al. with TP53 as the most common mutant gene correlated significantly with worse disease-free survival (DFS) of 6.7 versus 17.5 months (An et al. 2019).

\section{Methylation alterations of ctDNA in HCC}

Besides genetic alterations with change of DNA sequence, epigenetic silencing of tumor suppressor genes by promotor hypermethylation has been proven to be present in precursor lesions of HCC. Aberrant DNA hypermethylation consists of the addition of a methyl residue on cytosines preceding guanosines leading to a condensed chromatin structure without transcriptional activity. High concordance of DNA methylation in plasma and tumor DNA could be shown for a number of tumor suppressor genes in HCC (Iyer et al. 2010). Aberrant methylation of the cyclin-dependent kinase inhibitor genes p15 (CDKN2B or p15INK4b) and p16 (CDKN2A or p16INK4a) on chromosome 9p21 in the peripheral circulation of HCC patients using MSP is one of first detected epigenetic changes associated with hepatocellular tumorigenesis. Wong et al. detected concurrent p15 and p16 methylation in 74\% of ctDNA of 23 blood samples from $92 \%$ of HCC patients with tumor p15/p16 methylation (Wong et al. 1999, 2000). High incidence of p16INK4a promoter hypermethylation in ctDNA with significant decrease in postoperative blood samples was shown to be a useful marker in the detection and monitoring of $\mathrm{HCC}$ (Wong et al. 2003). Correspondingly, Huang et al. demonstrated higher levels of methylated p16INK4a in circulating cfDNA of 66 HCC serum samples versus 43 benign chronic liver diseases (Huang et al. 2014). Further common tumor suppressing and cell cycle regulation-related genes with promoter hypermethylation are the adenomatous polyposis coli (APC) on chromosome $5 \mathrm{q} 21$ and the Ras association domain family protein 1A (RASSF1A) genes on chromosome 3p21.3 with high frequency of promoter hypermethylation in tumor and blood samples of HCC patients (Hu et al. 2010; Huang et al. 2011; Yeo et al. 2005). Mohamed et al. as well as Mansour et al. could demonstrate that serum levels of methylated RASSF1A could well discriminate HCC patients from healthy volunteers and from chronic $\mathrm{HCV}$ infection with an incidence of about $90 \%$ in HCC serum samples (Mansour et al. 2017; Mohamed et al. 2012). Similar frequencies of methylated RASSF1A in serum of HCC patients at diagnosis or 1 year after tumor resection versus low concentrations in HBV carriers correlated with poorer disease-free survival (DFS) in a study of Chan et al. (Chan et al. 2008). Moreover, elevated plasma methylation levels of APC or RASSF1A correlated with poorer overall survival reaching significance for RASSF1A in multivariate analysis (Huang et al. 2011). Coevaluation of RASSF1A and Long Interspersed Nucleotide Element 1 (LINE-1) as one of the major repetitive DNA sequence of the human genome and most active mediator of retrotransposition revealed LINE-1 hypomethylation in $66.7 \%$ and RASSF1A promoter hypermethylation in $73.3 \%$ only in HCC serum DNA samples correlating with early recurrence and poor survival after curative resection (Liu et al. 2017). Tangkijvanich et al. described significantly increased serum LINE-1 hypomethylation in HCC as independent prognostic factor of overall survival (Tangkijvanich et al. 2007). Combined detection of ctDNA methylation markers was performed by several studies to improve the efficiency in early HCC diagnostic. Plasma methylation analysis of the four genes panel with APC, glutathione $S$-transferase P 1 (GSTP1), RASSF1A, and secreted frizzled-related protein 1 (SFRP1) resulted in an increased accuracy of $93 \%$ to differentiate between HCC and healthy controls (Huang et al. 2011). Xu et al. constructed a diagnostic prediction model using a cfDNA methylation marker panel that predicted HCC survival and could effectively discriminate patients with $\mathrm{HCC}$ from individuals with $\mathrm{HBV} /$ HCV infection, fatty liver disease as well as healthy controls superior to AFP (Xu et al. 2017). Although a multitude of aberrant methylated genes could be identified as prognostic target in HCC, there is no recognized biomarker confirmed in multiple centers (Han et al. 2014; Iizuka et al. 2011; Ji et al. 2014; Oussalah et al. 2018; Sun et al. 2013; Wang et al. 2006; Wen et al. 2015; Wu et al. 2017; Zhang et al. 2013). 


\section{Genomic alterations of ctDNA in PC}

In the last decade, comprehensive genomic analysis allowed important advances in the understanding of the molecular pathogenesis of $\mathrm{PC}$ with reclassification in different specific subtypes (Bailey et al. 2016; Biankin et al. 2012; Collisson et al. 2011; Jones et al. 2008; Moffitt et al. 2015; Waddell et al. 2015; Witkiewicz et al. 2015). Several studies using different techniques could reveal that reproducible molecular subgroups with consistent alterations in genes and signaling pathways are emerging in PC. Evaluating 456 specimens of resected PC by a combination of whole-genome sequencing and deep-exome sequencing, Bailey et al. identified genetic mutations particularly of KRAS in 92\%, cell cycle checkpoint mutations as TP53 and CDKN2A in 78\%, aberrations in TGF beta signaling as SMAD4, TGFBR1, and Activin A receptor 1B in $47 \%$, mutations leading to histone modification in $24 \%$, mutations in the Breast Cancer Gene (BRCA) pathway in $17 \%$, and mutations in the ATP-dependent chromatin remodeling complex as AT-rich interaction domain 1A (ARID1A) in 14\% (Bailey et al. 2016). However, there is still a lack of consensus in the clinical applicability of current PC subtyping approaches. Recently, plasma cfDNA profiling in 38 patients with advanced $\mathrm{PC}$ receiving firstline FOLFIRINOX chemotherapy could demonstrate that $65.8 \%$ of patients had at least one common driver gene alteration in KRAS, TP53, SMAD4, or CDKN2A in high concordance with corresponding tumor tissue (Table 2) (Wei et al. 2019). Interestingly, the dynamics of total cfDNA concentration correlated positively with tumor burden following chemotherapy and might be a promising tool for early response prediction and therapy surveillance in patients with advanced PC. Among these key genes, KRAS is the best characterized tumor-related gene in PC with the highest frequency of KRAS point mutations located in codon 12 and with appearance even at early stages of PC carcinogenesis (Almoguera et al. 1988; Rhim et al. 2014; Uemura et al. 2003). Therefore, KRAS mutant ctDNA represents a promising biomarker and therapeutic target of PC. Using ddPCR and targeted NGS, different KRAS mutations were detected in up to $80 \%$ of PC serum and plasma samples and were associated with decreased survival (Adamo et al. 2017; Ako et al. 2017; Chen et al. 2010; Cohen et al. 2017; Dabritz et al. 2009; Del Re et al. 2017; Dianxu et al. 2002; Earl et al. 2015; Hadano et al. 2016; Jiao et al. 2007; Kim et al. 2018; Kinugasa et al. 2015; Kruger et al. 2018; Lin et al. 2018; Maire et al. 2002; Marchese et al. 2006; Nakano et al. 2018; Park et al. 2018; Patel et al. 2019; Perets et al. 2018; Pratt et al. 2019; Riviere et al. 2018; Sausen et al. 2015; Semrad et al. 2015; Sugimori et al. 2020; Takai et al.
2015; Tjensvoll et al. 2016; Uemura et al. 2004; Van Laethem et al. 2017; Watanabe et al. 2019; Wu et al. 2014). Chen et al. published a KRAS mutant ctDNA detection rate of $93.7 \%$ which correlates with time to progression and overall survival of 189 patients with unresectable PC (Chen et al. 2017). In metastatic PC absence of KRAS mutant ctDNA was significantly associated with survival benefit of 37.5 versus 8 months $(p<0.004)$ (Perets et al. 2018). Correspondingly, PC patients with KRAS mutant ctDNA were more likely to relapse after curative surgery than those without KRAS mutant ctDNA with deseasefree survival of 6.1 versus 16.1 months and overall survival of 13.6 versus 27.6 months $(p<0.001$ ) (Groot et al. 2019; Hadano et al. 2016; Sausen et al. 2015). Serial plasma testing of KRAS mutant ctDNA in advanced PC patients receiving chemotherapy allowed the monitoring of rapid changes of KRAS mutant ctDNA levels superior to CA19-9 and CEA kinetics (Kruger et al. 2018). Targeting KRAS pathway is a promising effort to make therapeutic progress in PC (Krantz and O'Reilly 2018). Although mutant KRAS is often identified in plasma as a ctDNA benchmark for PC, advances in sequencing of the whole PC genomic landscape have expanded the panel of key mutations (Kanda et al. 2013; Pietrasz et al. 2017; Pishvaian et al. 2017; Yu et al. 2017; Zill et al. 2015). CtDNA whole-exome sequencing of 60 hotspot genes in metastatic PC identified KRAS, BRCA2, KDR, EGFR, and ERBB2 as candidate genetic mutations. DdPCR could validate ctDNA mutations at ERBB2 exon17 and KRAS G12V that were significantly correlated with worse overall survival (Cheng et al. 2017). Berger et al. performed NGS and ddPCR to dynamically monitor the most frequently ctDNA mutated genes in PC. TP53 and KRAS mutation levels were significantly decreased during treatment, and on the other hand significantly increased during tumor progression correlating with progression-free survival (Berger et al. 2018). However, current biomolecular technologies confirm the genetic heterogeneity of PC with a large number of low-frequently mutated loci and a large fraction of patients who does not harbor mutations in KRAS or TP53 (Martinez et al. 2013).

\section{Methylation alterations of ctDNA in PC}

Methylation analyses of ctDNA that reveal epigenetic alterations with more or less diagnostic and prognostic impact reflect the remarkable heterogeneity in PC patients. CfDNA promotor hypermethylation in plasma or serum could be detected in all stages of PC (Henriksen et al. 2017b). Henriksen et al. developed a survival prediction model based on plasma-derived cfDNA hypermethylation of a large gene panel that enables the stratification of patients into risk 
groups (Henriksen et al. 2017a). Further methylation analyses of ctDNA were able to differentiate PC from chronic pancreatitis and healthy controls (Henriksen et al. 2016; Liggett et al. 2010; Melnikov et al. 2009; Melson et al. 2014; Park et al. 2012). Confirming study results of Yi et al., Eissa et al. could show that a two-gene promotor methylation panel of Zinc finger protein basonuclin-1 (BNC1) and A disintegrin and metalloproteinase with thrombospondin motifs 1 (ADAMTS1) increased sensitivity to $97.4 \%$ and specificity to $91.6 \%$ in plasma cfDNA of early PC stages (Eissa et al. 2019; Yi et al. 2013). So far, in relatively, few PC patients no single ctDNA promotor hypermethylation with adequate sensitivity and specificity has been found. Furthermore, serial ctDNA studies following the methylation profile of PC patients in accordance with treatment and tumor recurrence are lacking.

\section{Challenges in clinical utility of circulating DNA}

CtDNA has gained considerable attention as novel liquid biopsy marker for cancer detection in asymptomatic individuals and of residual disease. Indeed, ctDNA has huge clinical potential for prognostication and response monitoring of patients with HCC and PC characterized by high tumor heterogeneity and dismal prognosis. However, although literature regarding ctDNA assays and molecular profiling is rapidly growing, its translation into clinical applicability is highly complex. Limited data are available regarding the blood draw procedure and pre-analytical variables that increase degradation of cfDNA or contamination by cellular genomic DNA derived from leukocyte lysis (Lee et al. 2001). Indeed, varying cfDNA purification methods and various protocol modifications may affect cfDNA yield and purity. There is consensus that cfDNA analysis requires special processing and handling by using cell-stabilization tubes and avoiding repeated freeze-thaw cycles. Furthermore, patient-related factors as medical treatment, smoking, exercise, age-related clonal hematopoiesis, inflammation or cardio-pulmonary disorders may contribute to the release of cfDNA. Interestingly, several studies could demonstrate that false-positive plasma genotyping is due to clonal hematopoiesis with non-malignant mutations harbored by hematopoietic cells with increasing frequency in $10 \%$ of patients over the age of 65 years, but only in $1 \%$ of patients under the age of 50 years (Hu et al. 2018; Jaiswal et al. 2014). The proportion of ctDNA as a fraction of cfDNA varies substantially between different patients, and different subclonal variants might be identified. Therefore, allele fractions of variants in ctDNA need to be interpreted with great caution.

In the last decade, numerous platforms for genotyping of cfDNA have been developed. However, the test characteristics of each platform as ddPCR and NGS vary and were validated in different patient populations with different lower limits of detection. Therefore, direct comparison of these platforms with reported high diagnostic specificity, but modest sensitivity is challenging and requires rigorous cross-assay comparisons. The low diagnostic sensitivity of ctDNA tests in carcinomas could be a major reason of discordant tissue and ctDNA genotyping results. Although clinical utility of ctDNA assays is mainly based on retrospective analyses, first FDA-approved application in 2018 for cfDNA assay in routine clinical practice could demonstrate high concordance between plasma and tumor tissue genotyping for early detection of specific EGFR mutation (T790M) and therapy stratification in advanced non-small cell lung cancer patients (Zhang et al. 2018). The concept of plasma genotyping is highly promising, although its application in the clinical routine to identify and treat patients with $\mathrm{HCC}$ or PC requires ongoing evaluation.

\section{Conclusion}

Overall, ctDNA mapping of somatic driver mutations and specific epigenetic alterations has great potential in early detection and dynamic monitoring of hepatic or pancreatic carcinomas to achieve a significant decrease of mortality. However, low sensitivity of current ctDNA assays rest a major challenge.

So far, ctDNA analysis in PC and HCC could reveal high frequency of common key mutations as TP53 and CDKN2A. CTNNB1 and TERT mutations and aberrant methylation of RASSF1A and CDKN2A were detected in ctDNA of HCC patients, whereas high frequency of KRAS mutations was characteristic for PC. Prospective trial data based on sufficient sample size and defined entry criteria regarding the blood draw procedure and pre-analytical variables as well as standardization of experimental techniques that demonstrate the clinical utility of ctDNA assays in PC and HCC are required.

Acknowledgements Open Access funding provided by Projekt DEAL.

Author contributions Conceptualization: SAD. Methodology: SAD and ZY. Validation: SAD. Investigation: SAD and ZY. Writingoriginal draft preparation: SAD and ZY. Writing—review and editing: SAD and ZY. Visualization: SAD and ZY. Supervision: SAD. Project administration: SAD.

Funding The authors declare that they have no funding to disclose.

Availability of data and material All data generated or analyzed during this study are included in this published article. 


\section{Compliance with ethical standards:}

Conflict of interest The authors declare that they have has no conflict of interest.

Ethical approval All procedures performed in studies involving human participants were in accordance with the ethical standards of the institutional and/or national research committee and with the 1964 Helsinki Declaration and its later amendments or comparable ethical standards. This article does not contain any studies with animals performed by any of the authors.

Informed consent Informed consent was obtained from all individual participants included in the study.

Open Access This article is licensed under a Creative Commons Attribution 4.0 International License, which permits use, sharing, adaptation, distribution and reproduction in any medium or format, as long as you give appropriate credit to the original author(s) and the source, provide a link to the Creative Commons licence, and indicate if changes were made. The images or other third party material in this article are included in the article's Creative Commons licence, unless indicated otherwise in a credit line to the material. If material is not included in the article's Creative Commons licence and your intended use is not permitted by statutory regulation or exceeds the permitted use, you will need to obtain permission directly from the copyright holder. To view a copy of this licence, visit http://creativecommons.org/licenses/by/4.0/.

\section{References}

Adamo P et al (2017) Profiling tumour heterogeneity through circulating tumour DNA in patients with pancreatic cancer. Oncotarget 8:87221-87233. https://doi.org/10.18632/oncotarget.20250

Ako $S$ et al (2017) Utility of serum DNA as a marker for KRAS mutations in pancreatic cancer tissue. Pancreatology 17:285-290. https://doi.org/10.1016/j.pan.2016.12.011

Almoguera C, Shibata D, Forrester K, Martin J, Arnheim N, Perucho M (1988) Most human carcinomas of the exocrine pancreas contain mutant c-K-ras genes. Cell 53:549-554. https://doi. org/10.1016/0092-8674(88)90571-5

An Y et al (2019) The diagnostic and prognostic usage of circulating tumor DNA in operable hepatocellular carcinoma Am J. Transl Res 11:6462-6474

Aucamp J, Bronkhorst AJ, Badenhorst CPS, Pretorius PJ (2018) The diverse origins of circulating cell-free DNA in the human body: a critical re-evaluation of the literature. Biol Rev Camb Philos Soc 93:1649-1683. https://doi.org/10.1111/brv.12413

Bailey P et al (2016) Genomic analyses identify molecular subtypes of pancreatic cancer. Nature 531:47-52. https://doi.org/10.1038/ nature 16965

Bell RJ, Rube HT, Xavier-Magalhaes A, Costa BM, Mancini A, Song JS, Costello JF (2016) Understanding TERT promoter mutations: a common path to immortality. Mol Cancer Res 14:315-323. https://doi.org/10.1158/1541-7786.MCR-16-0003

Berger AW et al (2018) Targeted deep sequencing of circulating tumor DNA in metastatic pancreatic cancer. Oncotarget 9:2076-2085. https://doi.org/10.18632/oncotarget.23330

Bergsmedh A, Szeles A, Henriksson M, Bratt A, Folkman MJ, Spetz AL, Holmgren L (2001) Horizontal transfer of oncogenes by uptake of apoptotic bodies. Proc Natl Acad Sci U S A 98:64076411. https://doi.org/10.1073/pnas.101129998

Bettegowda C et al (2014) Detection of circulating tumor DNA in early- and late-stage human malignancies. Sci Transl Med 6:224ra224. https://doi.org/10.1126/scitranslmed.3007094

Biankin AV et al (2012) Pancreatic cancer genomes reveal aberrations in axon guidance pathway genes. Nature 491:399-405. https:// doi.org/10.1038/nature11547

Bolondi L et al (2013) Position paper of the Italian Association for the Study of the Liver (AISF): the multidisciplinary clinical approach to hepatocellular carcinoma. Dig Liver Dis 45:712723. https://doi.org/10.1016/j.dld.2013.01.012

Botezatu I et al (2000) Genetic analysis of DNA excreted in urine: a new approach for detecting specific genomic DNA sequences from cells dying in an organism. Clin Chem 46:1078-1084

Bruhn N et al (2000) Detection of microsatellite alterations in the DNA isolated from tumor cells and from plasma DNA of patients with lung cancer. Ann N Y Acad Sci 906:72-82. https://doi. org/10.1111/j.1749-6632.2000.tb06594.x

Burris HA 3rd et al (1997) Improvements in survival and clinical benefit with gemcitabine as first-line therapy for patients with advanced pancreas cancer: a randomized trial. J Clin Oncol 15:2403-2413. https://doi.org/10.1200/JCO.1997.15.6.2403

Cancer Genome Atlas Research Network (2017) Comprehensive and Integrative Genomic Characterization of Hepatocellular Carcinoma. Cell 169:1327-1341.e1323. https://doi.org/10.1016/j. cell.2017.05.046

Chan KC, Lai PB, Mok TS, Chan HL, Ding C, Yeung SW, Lo YM (2008) Quantitative analysis of circulating methylated DNA as a biomarker for hepatocellular carcinoma. Clin Chem 54:15281536. https://doi.org/10.1373/clinchem.2008.104653

Chen H, Tu H, Meng ZQ, Chen Z, Wang P, Liu LM (2010) K-ras mutational status predicts poor prognosis in unresectable pancreatic cancer. Eur J Surg Oncol 36:657-662. https://doi. org/10.1016/j.ejso.2010.05.014

Chen I et al (2017) Ultrasensitive plasma ctDNA KRAS assay for detection, prognosis, and assessment of therapeutic response in patients with unresectable pancreatic ductal adenocarcinoma. Oncotarget 8:97769-97786. https://doi.org/10.18632/oncot arget. 22080

Cheng $\mathrm{H}$ et al (2017) Analysis of ctDNA to predict prognosis and monitor treatment responses in metastatic pancreatic cancer patients. Int J Cancer 140:2344-2350. https://doi.org/10.1002/ ijc. 30650

Chin V et al (2018) Chemotherapy and radiotherapy for advanced pancreatic cancer. Cochrane Database Syst Rev 3:CD011044. https ://doi.org/10.1002/14651858.CD011044.pub2

Chiu RW et al (2008) Noninvasive prenatal diagnosis of fetal chromosomal aneuploidy by massively parallel genomic sequencing of DNA in maternal plasma. Proc Natl Acad Sci U S A 105:2045820463. https://doi.org/10.1073/pnas.0810641105

Cohen JD et al (2017) Combined circulating tumor DNA and protein biomarker-based liquid biopsy for the earlier detection of pancreatic cancers. Proc Natl Acad Sci U S A 114:10202-10207. https ://doi.org/10.1073/pnas.1704961114

Collisson EA et al (2011) Subtypes of pancreatic ductal adenocarcinoma and their differing responses to therapy. Nat Med 17:500503. https://doi.org/10.1038/nm.2344

Conroy $\mathrm{T}$ et al (2011) FOLFIRINOX versus gemcitabine for metastatic pancreatic cancer. N Engl J Med 364:1817-1825. https:// doi.org/10.1056/NEJMoa1011923

Cui Y et al (2012) Genetically defined subsets of human pancreatic cancer show unique in vitro chemosensitivity. Clin Cancer Res 18:6519-6530. https://doi.org/10.1158/1078-0432.CCR-12-0827 
Dabritz J, Preston R, Hanfler J, Oettle H (2009) Follow-up study of K-ras mutations in the plasma of patients with pancreatic cancer: correlation with clinical features and carbohydrate antigen 19-9. Pancreas 38:534-541. https://doi.org/10.1097/MPA.0b013 e31819f6376

Dianxu F, Shengdao Z, Tianquan H, Yu J, Ruoqing L, Zurong Y, Xuezhi W (2002) A prospective study of detection of pancreatic carcinoma by combined plasma K-ras mutations and serum CA19-9 analysis. Pancreas 25:336-341. https://doi. org/10.1097/00006676-200211000-00003

Diaz LA Jr, Bardelli A (2014) Liquid biopsies: genotyping circulating tumor DNA. J Clin Oncol 32:579-586. https://doi.org/10.1200/ JCO.2012.45.2011

Diehl F et al (2008) Circulating mutant DNA to assess tumor dynamics. Nat Med 14:985-990. https://doi.org/10.1038/nm.1789

Downward J (2003) Targeting RAS signalling pathways in cancer therapy. Nat Rev Cancer 3:11-22. https://doi.org/10.1038/nrc969

Earl J et al (2015) Circulating tumor cells (Ctc) and kras mutant circulating free Dna (cfdna) detection in peripheral blood as biomarkers in patients diagnosed with exocrine pancreatic cancer. BMC Cancer 15:797. https://doi.org/10.1186/s12885-015-1779-7

Eissa MAL et al (2019) Promoter methylation of ADAMTS1 and $\mathrm{BNC1}$ as potential biomarkers for early detection of pancreatic cancer in blood. Clin Epigenet 11:59. https://doi.org/10.1186/ s13148-019-0650-0

El-Deiry WS et al (2019) The current state of molecular testing in the treatment of patients with solid tumors. CA Cancer J Clin 69:305-343. https://doi.org/10.3322/caac.21560

Fleischhacker M, Schmidt B (2007) Circulating nucleic acids (CNAs) and cancer-a survey. Biochim Biophys Acta 1775:181-232. https://doi.org/10.1016/j.bbcan.2006.10.001

Forner A, Reig M, Bruix J (2018) Hepatocellular carcinoma. Lancet 391:1301-1314. https://doi.org/10.1016/S0140-6736(18)30010-2

Gahan PB, Stroun M (2010) The virtosome-a novel cytosolic informative entity and intercellular messenger. Cell Biochem Funct 28:529-538. https://doi.org/10.1002/cbf.1690

Gamil M et al (2018) Novel scores combining AFP with non-invasive markers for prediction of liver fibrosis in chronic hepatitis $\mathrm{C}$ patients. J Med Virol 90:1080-1086. https://doi.org/10.1002/ jmv. 25026

Garcia-Olmo D, Garcia-Olmo DC, Ontanon J, Martinez E, Vallejo M (1999) Tumor DNA circulating in the plasma might play a role in metastasis. The hypothesis of the genometastasis. Histol Histopathol 14:1159-1164. https://doi.org/10.14670/HH-14.1159

Groot VP et al (2019) Circulating tumor DNA as a clinical test in resected pancreatic cancer. Clin Cancer Res 25:4973-4984. https ://doi.org/10.1158/1078-0432.CCR-19-0197

Grutzmann R et al (2008) Sensitive detection of colorectal cancer in peripheral blood by septin 9 DNA methylation assay. PLoS ONE 3:e3759. https://doi.org/10.1371/journal.pone.0003759

Guo S, Diep D, Plongthongkum N, Fung HL, Zhang K (2017) Identification of methylation haplotype blocks aids in deconvolution of heterogeneous tissue samples and tumor tissue-of-origin mapping from plasma DNA. Nat Genet 49:635-642. https://doi. org/10.1038/ng.3805

Hadano N et al (2016) Prognostic value of circulating tumour DNA in patients undergoing curative resection for pancreatic cancer. Br J Cancer 115:59-65. https://doi.org/10.1038/bjc.2016.175

Han LY et al (2014) Aberrant DNA methylation of G-protein-coupled bile acid receptor Gpbar1 (TGR5) is a potential biomarker for hepatitis B Virus associated hepatocellular carcinoma. Int J Med Sci 11:164-171. https://doi.org/10.7150/ijms.6745

He G, Chen Y, Zhu C, Zhou J, Xie X, Fei R, Wei L, Zhao H, Chen H, Zhang H (2019) Application of plasma circulating cell-free DNA detection to the molecular diagnosis of hepatocellular carcinoma. Am J Transl Res 11(3):1428-1445
Heitzer E, Ulz P, Geigl JB (2015) Circulating tumor DNA as a liquid biopsy for cancer. Clin Chem 61:112-123. https://doi. org/10.1373/clinchem.2014.222679

Henriksen SD et al (2016) Cell-free DNA promoter hypermethylation in plasma as a diagnostic marker for pancreatic adenocarcinoma. Clin Epigenet 8:117. https://doi.org/10.1186/s13148-016-0286-2

Henriksen SD, Madsen PH, Larsen AC, Johansen MB, Pedersen IS, Krarup H, Thorlacius-Ussing O (2017a) Cell-free DNA promoter hypermethylation in plasma as a predictive marker for survival of patients with pancreatic adenocarcinoma. Oncotarget 8:9394293956. https://doi.org/10.18632/oncotarget.21397

Henriksen SD, Madsen PH, Larsen AC, Johansen MB, Pedersen IS, Krarup H, Thorlacius-Ussing O (2017b) Promoter hypermethylation in plasma-derived cell-free DNA as a prognostic marker for pancreatic adenocarcinoma staging. Int J Cancer 141:2489-2497. https://doi.org/10.1002/ijc.31024

Hindson BJ et al (2011) High-throughput droplet digital PCR system for absolute quantitation of DNA copy number. Anal Chem 83:8604-8610. https://doi.org/10.1021/ac202028g

Hu L, Chen G, Yu H, Qiu X (2010) Clinicopathological significance of RASSF1A reduced expression and hypermethylation in hepatocellular carcinoma. Hepatol Int 4:423-432. https://doi. org/10.1007/s12072-010-9164-8

$\mathrm{Hu}$ Y et al (2018) False-Positive Plasma Genotyping Due to Clonal Hematopoiesis. Clin Cancer Res 24:4437-4443. https://doi. org/10.1158/1078-0432.CCR-18-0143

Huang ZH, Hu Y, Hua D, Wu YY, Song MX, Cheng ZH (2011) Quantitative analysis of multiple methylated genes in plasma for the diagnosis and prognosis of hepatocellular carcinoma. Exp Mol Pathol 91:702-707. https://doi.org/10.1016/j.yexmp.2011.08.004

Huang G et al (2014) Evaluation of INK4A promoter methylation using pyrosequencing and circulating cell-free DNA from patients with hepatocellular carcinoma. Clin Chem Lab Med 52:899-909. https://doi.org/10.1515/cclm-2013-0885

Huang A et al (2016) Detecting circulating tumor DNA in hepatocellular carcinoma patients using droplet digital pcr is feasible and reflects intratumoral heterogeneity. J Cancer 7:1907-1914. https ://doi.org/10.7150/jca. 15823

Huggett JF, Cowen S, Foy CA (2015) Considerations for digital PCR as an accurate molecular diagnostic tool. Clin Chem 61:79-88. https://doi.org/10.1373/clinchem.2014.221366

Iizuka $\mathrm{N}$ et al (2011) Efficient detection of hepatocellular carcinoma by a hybrid blood test of epigenetic and classical protein markers. Clin Chim Acta 412:152-158. https://doi.org/10.1016/j. cca.2010.09.028

Ikeda S, Lim JS, Kurzrock R (2018a) Analysis of tissue and circulating tumor DNA by next-generation sequencing of hepatocellular carcinoma: implications for targeted therapeutics. Mol Cancer Ther 17:1114-1122. https://doi.org/10.1158/1535-7163.MCT-17-0604

Ikeda S et al (2018b) Next-generation sequencing of circulating tumor DNA reveals frequent alterations in advanced hepatocellular carcinoma. Oncologist 23:586-593. https://doi.org/10.1634/theon cologist.2017-0479

Iyer $\mathrm{P}$ et al (2010) Concordance of DNA methylation pattern in plasma and tumor DNA of Egyptian hepatocellular carcinoma patients. Exp Mol Pathol 88:107-111. https://doi.org/10.1016/j.yexmp .2009.09.012

Jahr S, Hentze H, Englisch S, Hardt D, Fackelmayer FO, Hesch RD, Knippers R (2001) DNA fragments in the blood plasma of cancer patients: quantitations and evidence for their origin from apoptotic and necrotic cells. Cancer Res 61:1659-1665

Jaiswal S et al (2014) Age-related clonal hematopoiesis associated with adverse outcomes. N Engl J Med 371:2488-2498. https://doi. org/10.1056/NEJMoa1408617

Ji XF, Fan YC, Gao S, Yang Y, Zhang JJ, Wang K (2014) MT1M and MT1G promoter methylation as biomarkers for hepatocellular 
carcinoma. World J Gastroenterol 20:4723-4729. https://doi. org/10.3748/wjg.v20.i16.4723

Jiao L, Zhu J, Hassan MM, Evans DB, Abbruzzese JL, Li D (2007) K-ras mutation and p16 and preproenkephalin promoter hypermethylation in plasma DNA of pancreatic cancer patients: in relation to cigarette smoking. Pancreas 34:55-62. https://doi. org/10.1097/01.mpa.0000246665.68869.d4

Jones S et al (2008) Core signaling pathways in human pancreatic cancers revealed by global genomic analyses. Science 321:18011806. https://doi.org/10.1126/science.1164368

Jung M, Klotzek S, Lewandowski M, Fleischhacker M, Jung K (2003) Changes in concentration of DNA in serum and plasma during storage of blood samples. Clin Chem 49:1028-1029

Kanda M et al (2013) Mutant TP53 in duodenal samples of pancreatic juice from patients with pancreatic cancer or high-grade dysplasia. Clin Gastroenterol Hepatol 11(719-730):e715. https://doi. org/10.1016/j.cgh.2012.11.016

Karapetis CS et al (2008) K-ras mutations and benefit from cetuximab in advanced colorectal cancer. N Engl J Med 359:1757-1765. https://doi.org/10.1056/NEJMoa0804385

Kaseb AO, Sánchez NS, Sen S, Kelley RK, Tan B, Bocobo AG, Lim KH, Abdel-Wahab R, Uemura M, Pestana RC, Qiao W, Xiao L, Morris J, Amin HM, Hassan MM, Rashid A, Banks KC, Lanman RB, Talasaz A, Mills-Shaw KR, George B, Haque A, Raghav KPS, Wolff RA, Yao JC, Meric-Bernstam F, Ikeda S, Kurzrock $\mathrm{R}$ (2019) Molecular profiling of hepatocellular carcinoma using circulating cell-free DNA. Clin Cancer Res 25(20):6107-6118. https://doi.org/10.1158/1078-0432.CCR-18-3341

Kim MK et al (2018) Prognostic implications of multiplex detection of KRAS mutations in cell-free DNA from patients with pancreatic ductal adenocarcinoma. Clin Chem 64:726-734. https://doi. org/10.1373/clinchem.2017.283721

Kimbi GC, Kew MC, Yu MC, Arakawa K, Hodkinson J (2005) 249ser p53 mutation in the serum of black southern African patients with hepatocellular carcinoma. J Gastroenterol Hepatol 20:11851190. https://doi.org/10.1111/j.1440-1746.2005.03951.x

Kinugasa $\mathrm{H}$ et al (2015) Detection of K-ras gene mutation by liquid biopsy in patients with pancreatic cancer. Cancer 121:22712280. https://doi.org/10.1002/cncr.29364

Krantz BA, O'Reilly EM (2018) Biomarker-based therapy in pancreatic ductal adenocarcinoma: an emerging reality? Clin Cancer Res 24:2241-2250. https://doi.org/10.1158/1078-0432.CCR-16-3169

Kruger $\mathrm{S}$ et al (2018) Repeated mutKRAS ctDNA measurements represent a novel and promising tool for early response prediction and therapy monitoring in advanced pancreatic cancer. Ann Oncol 29:2348-2355. https://doi.org/10.1093/annonc/mdy417

Van Laethem JL et al (2017) Phase I/II study of refametinib (BAY 86-9766) in combination with gemcitabine in advanced pancreatic cancer. Target Oncol 12:97-109. https://doi.org/10.1007/ s11523-016-0469-y

Leary RJ et al (2010) Development of personalized tumor biomarkers using massively parallel sequencing. Sci Transl Med 2:20ra14. https://doi.org/10.1126/scitranslmed.3000702

Lee TH, Montalvo L, Chrebtow V, Busch MP (2001) Quantitation of genomic DNA in plasma and serum samples: higher concentrations of genomic DNA found in serum than in plasma. Transfusion 41:276-282. https://doi.org/10.104 6/j.1537-2995.2001.41020276.x

Leon SA, Shapiro B, Sklaroff DM, Yaros MJ (1977) Free DNA in the serum of cancer patients and the effect of therapy. Cancer Res 37:646-650

Liao PH, Chang YC, Huang MF, Tai KW, Chou MY (2000) Mutation of p53 gene codon 63 in saliva as a molecular marker for oral squamous cell carcinomas. Oral Oncol 36:272-276. https://doi. org/10.1016/s1368-8375(00),00005-1
Liao W et al (2016) Noninvasive detection of tumor-associated mutations from circulating cell-free DNA in hepatocellular carcinoma patients by targeted deep sequencing. Oncotarget 7:4048140490. https://doi.org/10.18632/oncotarget.9629

Liggett $\mathrm{T}$ et al (2010) Differential methylation of cell-free circulating DNA among patients with pancreatic cancer versus chronic pancreatitis. Cancer 116:1674-1680. https://doi.org/10.1002/ cncr.24893

Lin SY et al (2011) A locked nucleic acid clamp-mediated PCR assay for detection of a p53 codon 249 hotspot mutation in urine. J Mol Diagn 13:474-484. https://doi.org/10.1016/j.jmoldx.2011.05.005

Lin M et al (2018) Circulating tumor DNA as a sensitive marker in patients undergoing irreversible electroporation for pancreatic cancer. Cell Physiol Biochem 47:1556-1564. https://doi. org/10.1159/000490874

Liu ZJ et al (2017) Combination of LINE-1 hypomethylation and RASSF1A promoter hypermethylation in serum DNA is a noninvasion prognostic biomarker for early recurrence of hepatocellular carcinoma after curative resection. Neoplasma 64:795-802. https://doi.org/10.4149/neo_2017_519

Llovet JM et al (2008) Sorafenib in advanced hepatocellular carcinoma. N Engl J Med 359:378-390. https://doi.org/10.1056/NEJMo a0708857

Lo YM, Corbetta N, Chamberlain PF, Rai V, Sargent IL, Redman CW, Wainscoat JS (1997) Presence of fetal DNA in maternal plasma and serum. Lancet 350:485-487. https://doi.org/10.1016/S0140 -6736(97)02174-0

Lo YM, Tein MS, Pang CC, Yeung CK, Tong KL, Hjelm NM (1998) Presence of donor-specific DNA in plasma of kidney and liver-transplant recipients. Lancet 351:1329-1330. https://doi. org/10.1016/s0140-6736(05)79055-3

Madic J et al (2012) Pyrophosphorolysis-activated polymerization detects circulating tumor DNA in metastatic uveal melanoma. Clin Cancer Res 18:3934-3941. https://doi.org/10.1158/10780432.CCR-12-0309

Maire F et al (2002) Differential diagnosis between chronic pancreatitis and pancreatic cancer: value of the detection of KRAS2 mutations in circulating DNA. Br J Cancer 87:551-554. https ://doi.org/10.1038/sj.bjc.6600475

Mandel P, Metais P (1948) Les acides nucleiques du plasma sanguin chez l'homme. C R Seances Soc Biol Fil 142:241-243

Mansour LA, El Raziky M, Mohamed AA, Mahmoud EH, Hamdy S, El Sayed EH (2017) Circulating hypermethylated RASSF1A as a molecular biomarker for diagnosis of hepatocellular carcinoma. Asian Pac J Cancer Prev 18:1637-1643. https://doi. org/10.22034/APJCP.2017.18.6.1637

Mao L, Hruban RH, Boyle JO, Tockman M, Sidransky D (1994) Detection of oncogene mutations in sputum precedes diagnosis of lung cancer. Cancer Res 54:1634-1637

Marchese R et al (2006) Low correspondence between K-ras mutations in pancreatic cancer tissue and detection of K-ras mutations in circulating DNA. Pancreas 32:171-177. https://doi. org/10.1097/01.mpa.0000202938.63084.e3

Marchio A et al (2018) Droplet digital PCR detects high rate of TP53 R249S mutants in cell-free DNA of middle African patients with hepatocellular carcinoma. Clin Exp Med 18:421-431. https://doi.org/10.1007/s10238-018-0502-9

Martinez P, McGranahan N, Birkbak NJ, Gerlinger M, Swanton C (2013) Computational optimisation of targeted DNA sequencing for cancer detection. Sci Rep 3:3309. https://doi. org/10.1038/srep03309

Melnikov AA, Scholtens D, Talamonti MS, Bentrem DJ, Levenson VV (2009) Methylation profile of circulating plasma DNA in patients with pancreatic cancer. J Surg Oncol 99:119-122. https://doi.org/10.1002/jso.21208 
Melo SA et al (2015) Glypican-1 identifies cancer exosomes and detects early pancreatic cancer. Nature 523:177-182. https:// doi.org/10.1038/nature14581

Melson J et al (2014) Commonality and differences of methylation signatures in the plasma of patients with pancreatic cancer and colorectal cancer. Int J Cancer 134:2656-2662. https:// doi.org/10.1002/ijc. 28593

Minchin RF, Carpenter D, Orr RJ (2001) Polyinosinic acid and polycationic liposomes attenuate the hepatic clearance of circulating plasmid DNA. J Pharmacol Exp Ther 296:1006-1012

Moffitt RA et al (2015) Virtual microdissection identifies distinct tumor- and stroma-specific subtypes of pancreatic ductal adenocarcinoma. Nat Genet 47:1168-1178. https://doi. org/10.1038/ng.3398

Mohamed NA, Swify EM, Amin NF, Soliman MM, Tag-Eldin LM, Elsherbiny NM (2012) Is serum level of methylated RASSF1A valuable in diagnosing hepatocellular carcinoma in patients with chronic viral hepatitis C? Arab J Gastroenterol 13:111115. https://doi.org/10.1016/j.ajg.2012.06.009

Moore MJ et al (2007) Erlotinib plus gemcitabine compared with gemcitabine alone in patients with advanced pancreatic cancer: a phase III trial of the National Cancer Institute of Canada Clinical Trials Group. J Clin Oncol 25:1960-1966. https://doi. org/10.1200/JCO.2006.07.9525

Murtaza M et al (2013) Non-invasive analysis of acquired resistance to cancer therapy by sequencing of plasma DNA. Nature 497:108-112. https://doi.org/10.1038/nature12065

Nakano Y et al (2018) KRAS mutations in cell-free DNA from preoperative and postoperative sera as a pancreatic cancer marker: a retrospective study. Br J Cancer 118:662-669. https://doi. org/10.1038/bjc.2017.479

Nault JC, Villanueva A (2015) Intratumor molecular and phenotypic diversity in hepatocellular carcinoma. Clin Cancer Res 21:17861788. https://doi.org/10.1158/1078-0432.CCR-14-2602

Nault JC et al (2013) High frequency of telomerase reverse-transcriptase promoter somatic mutations in hepatocellular carcinoma and preneoplastic lesions. Nat Commun 4:2218. https:// doi.org/10.1038/ncomms3218

Oussalah A et al (2018) Plasma mSEPT9: a novel circulating cell-free DNA-based epigenetic biomarker to diagnose hepatocellular carcinoma. EBioMedicine 30:138-147. https://doi.org/10.1016/j. ebiom.2018.03.029

Ozen C et al (2013) Genetics and epigenetics of liver cancer. N Biotechnol 30:381-384. https://doi.org/10.1016/j.nbt.2013.01.007

Park JK et al (2012) The role of quantitative NPTX2 hypermethylation as a novel serum diagnostic marker in pancreatic cancer. Pancreas 41:95-101. https://doi.org/10.1097/MPA.0b013e3182 21c903

Park G et al (2018) Utility of targeted deep sequencing for detecting circulating tumor DNA in pancreatic cancer patients. Sci Rep 8:11631. https://doi.org/10.1038/s41598-018-30100-w

Patel $\mathrm{H}$ et al (2019) Clinical correlates of blood-derived circulating tumor DNA in pancreatic cancer. J Hematol Oncol 12:130. https ://doi.org/10.1186/s13045-019-0824-4

Perets R et al (2018) Mutant KRAS circulating tumor DNA is an accurate tool for pancreatic cancer monitoring. Oncologist 23:566572. https://doi.org/10.1634/theoncologist.2017-0467

Pietrasz D et al (2017) Plasma circulating tumor DNA in pancreatic cancer patients is a prognostic marker. Clin Cancer Res 23:116 123. https://doi.org/10.1158/1078-0432.CCR-16-0806

Pishvaian MJ et al (2017) A pilot study evaluating concordance between blood-based and patient-matched tumor molecular testing within pancreatic cancer patients participating in the Know Your Tumor (KYT) initiative. Oncotarget 8:83446-83456. https ://doi.org/10.18632/oncotarget.13225
Poruk KE, Firpo MA, Adler DG, Mulvihill SJ (2013) Screening for pancreatic cancer: why, how, and who? Ann Surg 257:17-26. https://doi.org/10.1097/SLA.0b013e31825ffbfb

Pratt ED, Cowan RW, Manning SL, Qiao E, Cameron H, Schradle K, Simeone DM, Zhen DB (2019) Multiplex enrichment and detection of rare KRAS mutations in liquid biopsy samples using digital droplet pre-amplification. Anal Chem 91(12):7516-7523. https://doi.org/10.1021/acs.analchem.8b01605

Rahib L, Smith BD, Aizenberg R, Rosenzweig AB, Fleshman JM, Matrisian LM (2014) Projecting cancer incidence and deaths to 2030: the unexpected burden of thyroid, liver, and pancreas cancers in the United States. Cancer Res 74:2913-2921. https://doi. org/10.1158/0008-5472.CAN-14-0155

Del Re M et al (2017) Early changes in plasma DNA levels of mutant KRAS as a sensitive marker of response to chemotherapy in pancreatic cancer. Sci Rep 7:7931. https://doi.org/10.1038/s4159 8-017-08297-z

Reni M et al (2005) Gemcitabine versus cisplatin, epirubicin, fluorouracil, and gemcitabine in advanced pancreatic cancer: a randomised controlled multicentre phase III trial. Lancet Oncol 6:369-376. https://doi.org/10.1016/S1470-2045(05),70175-3

Rhim AD et al (2014) Detection of circulating pancreas epithelial cells in patients with pancreatic cystic lesions. Gastroenterology 146:647-651. https://doi.org/10.1053/j.gastro.2013.12.007

Riviere P, Fanta PT, Ikeda S, Baumgartner J, Heestand GM, Kurzrock $\mathrm{R}$ (2018) The mutational landscape of gastrointestinal malignancies as reflected by circulating tumor DNA. Mol Cancer Ther 17:297-305. https://doi.org/10.1158/1535-7163.MCT-17-0360

Ryan DP, Hong TS, Bardeesy N (2014) Pancreatic adenocarcinoma. N Engl J Med 371:2140-2141. https://doi.org/10.1056/NEJMc 1412266

Sausen M, Parpart S, Diaz LA Jr (2014) Circulating tumor DNA moves further into the spotlight. Genome Med 6:35. https://doi. org/10.1186/gm552

Sausen M et al (2015) Clinical implications of genomic alterations in the tumour and circulation of pancreatic cancer patients. Nat Commun 6:7686. https://doi.org/10.1038/ncomms8686

Schwarzenbach H, Hoon DS, Pantel K (2011) Cell-free nucleic acids as biomarkers in cancer patients. Nat Rev Cancer 11:426-437. https://doi.org/10.1038/nrc3066

Semrad T et al (2015) Pharmacodynamic separation of gemcitabine and erlotinib in locally advanced or metastatic pancreatic cancer: therapeutic and biomarker results. Int J Clin Oncol 20:518-524. https://doi.org/10.1007/s10147-014-0730-2

Shapiro B, Chakrabarty M, Cohn EM, Leon SA (1983) Determination of circulating DNA levels in patients with benign or malignant gastrointestinal disease. Cancer 51:2116-2120. https ://doi.org/10.1002/1097-0142(19830601)51:11\%3c2116:aidcncr2820511127\%3e3.0.co;2-s

Siegel RL, Miller KD, Jemal A (2019) Cancer statistics, 2019. CA Cancer J Clin 69:7-34. https://doi.org/10.3322/caac.21551

Snyder TM, Khush KK, Valantine HA, Quake SR (2011) Universal noninvasive detection of solid organ transplant rejection. Proc Natl Acad Sci U S A 108:6229-6234. https://doi.org/10.1073/ pnas. 1013924108

Sorenson GD, Pribish DM, Valone FH, Memoli VA, Bzik DJ, Yao SL (1994) Soluble normal and mutated DNA sequences from single-copy genes in human blood. Cancer Epidemiol Biomark Prev 3:67-71

Stathopoulos GP et al (2006) A multicenter phase III trial comparing irinotecan-gemcitabine (IG) with gemcitabine (G) monotherapy as first-line treatment in patients with locally advanced or metastatic pancreatic cancer. Br J Cancer 95:587-592. https ://doi.org/10.1038/sj.bjc.6603301

Stigliano R, Burroughs AK (2005) Should we biopsy each liver mass suspicious for HCC before liver transplantation?-no, 
please don't. J Hepatol 43:563-568. https://doi.org/10.1016/j. jhep.2005.07.015

Stroun M, Anker P, Maurice P, Lyautey J, Lederrey C, Beljanski M (1989) Neoplastic characteristics of the DNA found in the plasma of cancer patients. Oncology 46:318-322. https://doi. org/10.1159/000226740

Sugimori M et al (2020) Quantitative monitoring of circulating tumor DNA in patients with advanced pancreatic cancer undergoing chemotherapy. Cancer Sci 111:266-278. https:// doi.org/10.1111/cas.14245

Sun FK et al (2013) Detection of TFPI2 methylation in the serum of hepatocellular carcinoma patients. Dig Dis Sci 58:1010-1015. https://doi.org/10.1007/s10620-012-2462-3

Sun K et al (2015) Plasma DNA tissue mapping by genome-wide methylation sequencing for noninvasive prenatal, cancer, and transplantation assessments. Proc Natl Acad Sci U S A 112:E5503-5512. https://doi.org/10.1073/pnas.1508736112

Szymanska K et al (2004) Ser-249TP53 mutation in tumour and plasma DNA of hepatocellular carcinoma patients from a high incidence area in the Gambia. West Africa Int J Cancer 110:374-379. https://doi.org/10.1002/ijc.20103

Takai E, Totoki Y, Nakamura H, Morizane C, Nara S, Hama N, Suzuki M, Furukawa E, Kato M, Hayashi H, Kohno T, Ueno H, Shimada K, Okusaka T, Nakagama H, Shibata T, Yachida S (2015) Clinical utility of circulating tumor DNA for molecular assessment in pancreatic cancer. Sci Rep 5:18425. https://doi.org/10.1038/ srep 18425

Tamkovich SN, Cherepanova AV, Kolesnikova EV, Rykova EY, Pyshnyi DV, Vlassov VV, Laktionov PP (2006) Circulating DNA and DNase activity in human blood. Ann N Y Acad Sci 1075:191-196. https://doi.org/10.1196/annals.1368.026

Tangkijvanich P, Hourpai N, Rattanatanyong P, Wisedopas N, Mahachai V, Mutirangura A (2007) Serum LINE-1 hypomethylation as a potential prognostic marker for hepatocellular carcinoma. Clin Chim Acta 379:127-133. https://doi.org/10.1016/j. cca.2006.12.029

Tjensvoll K et al (2016) Clinical relevance of circulating KRAS mutated DNA in plasma from patients with advanced pancreatic cancer. Mol Oncol 10:635-643. https://doi.org/10.1016/j. molonc.2015.11.012

Uemura K, Hiyama E, Murakami Y, Kanehiro T, Ohge H, Sueda T, Yokoyama T (2003) Comparative analysis of K-ras point mutation, telomerase activity, and p53 overexpression in pancreatic tumours. Oncol Rep 10:277-283

Uemura T et al (2004) Detection of K-ras mutations in the plasma DNA of pancreatic cancer patients. J Gastroenterol 39:56-60. https:// doi.org/10.1007/s00535-003-1245-1

Von Hoff DD et al (2013) Increased survival in pancreatic cancer with nab-paclitaxel plus gemcitabine. N Engl J Med 369:1691-1703. https://doi.org/10.1056/NEJMoa1304369

Villanueva A (2019) Hepatocellular Carcinoma. N Engl J Med 380:1450-1462. https://doi.org/10.1056/NEJMra1713263

Waddell $\mathrm{N}$ et al (2015) Whole genomes redefine the mutational landscape of pancreatic cancer. Nature 518:495-501. https://doi. org/10.1038/nature14169

Wang J, Qin Y, Li B, Sun Z, Yang B (2006) Detection of aberrant promoter methylation of GSTP1 in the tumor and serum of Chinese human primary hepatocellular carcinoma patients. Clin Biochem 39:344-348. https://doi.org/10.1016/j.clinbiochem.2006.01.008

Watanabe F et al (2019) Longitudinal monitoring of KRAS-mutated circulating tumor DNA enables the prediction of prognosis and therapeutic responses in patients with pancreatic cancer. PLoS ONE 14:e0227366. https://doi.org/10.1371/journal.pone.02273 66

Wei T et al (2019) Monitoring tumor burden in response to FOLFIRINOX chemotherapy via profiling circulating cell-free DNA in pancreatic cancer. Mol Cancer Ther 18:196-203. https://doi. org/10.1158/1535-7163.MCT-17-1298

Wen L et al (2015) Genome-scale detection of hypermethylated CpG islands in circulating cell-free DNA of hepatocellular carcinoma patients. Cell Res 25:1376. https://doi.org/10.1038/cr.2015.141

Witkiewicz AK et al (2015) Whole-exome sequencing of pancreatic cancer defines genetic diversity and therapeutic targets. Nat Commun 6:6744. https://doi.org/10.1038/ncomms7744

Wong IH et al (1999) Detection of aberrant p16 methylation in the plasma and serum of liver cancer patients. Cancer Res 59:71-73

Wong IH, Lo YM, Yeo W, Lau WY, Johnson PJ (2000) Frequent p15 promoter methylation in tumor and peripheral blood from hepatocellular carcinoma patients. Clin Cancer Res 6:3516-3521

Wong IH, Zhang J, Lai PB, Lau WY, Lo YM (2003) Quantitative analysis of tumor-derived methylated p16INK4a sequences in plasma, serum, and blood cells of hepatocellular carcinoma patients. Clin Cancer Res 9:1047-1052

$\mathrm{Wu} \mathrm{J}$ et al (2014) Co-amplification at lower denaturation-temperature PCR combined with unlabled-probe high-resolution melting to detect KRAS codon 12 and 13 mutations in plasma-circulating DNA of pancreatic adenocarcinoma cases. Asian Pac J Cancer Prev 15:10647-10652. https://doi.org/10.7314/apjcp .2014.15.24.10647

Wu HC, Yang HI, Wang Q, Chen CJ, Santella RM (2017) Plasma DNA methylation marker and hepatocellular carcinoma risk prediction model for the general population. Carcinogenesis 38:1021-1028. https://doi.org/10.1093/carcin/bgx078

Xiong Y, Xie CR, Zhang S, Chen J, Yin ZY (2019) Detection of a novel panel of somatic mutations in plasma cell-free DNA and its diagnostic value in hepatocellular carcinoma. Cancer Manag Res 11:5745-5756. https://doi.org/10.2147/CMAR.S197455

$\mathrm{Xu}$ RH et al (2017) Circulating tumour DNA methylation markers for diagnosis and prognosis of hepatocellular carcinoma. Nat Mater 16:1155-1161. https://doi.org/10.1038/nmat4997

Yeo W, Wong N, Wong WL, Lai PB, Zhong S, Johnson PJ (2005) High frequency of promoter hypermethylation of RASSF1A in tumor and plasma of patients with hepatocellular carcinoma. Liver Int 25:266-272. https://doi.org/10.1111/j.1478-3231.2005.01084.x

Yi JM et al (2013) Novel methylation biomarker panel for the early detection of pancreatic cancer. Clin Cancer Res 19:6544-6555. https://doi.org/10.1158/1078-0432.CCR-12-3224

Yoshida T, Yamashita Y, Kitano M (2019) Endoscopic ultrasound for early diagnosis of pancreatic cancer. Diagnostics (Basel). https ://doi.org/10.3390/diagnostics9030081

Yu SC, Lee SW, Jiang P, Leung TY, Chan KC, Chiu RW, Lo YM (2013) High-resolution profiling of fetal DNA clearance from maternal plasma by massively parallel sequencing. Clin Chem 59:1228-1237. https://doi.org/10.1373/clinchem.2013.203679

$\mathrm{Yu} J$ et al (2017) Digital next-generation sequencing identifies lowabundance mutations in pancreatic juice samples collected from the duodenum of patients with pancreatic cancer and intraductal papillary mucinous neoplasms. Gut 66:1677-1687. https://doi. org/10.1136/gutjnl-2015-311166

Zhang P et al (2013) Methylation profiling of serum DNA from hepatocellular carcinoma patients using an Infinium Human Methylation 450 BeadChip. Hepatol Int 7:893-900. https://doi. org/10.1007/s12072-013-9437-0

Zhang BO et al (2015) Comparison of droplet digital PCR and conventional quantitative PCR for measuring EGFR gene mutation. Exp Ther Med 9:1383-1388. https://doi.org/10.3892/etm.2015.2221

Zhang S et al (2018) Epidermal growth factor receptor (EGFR) T790M mutation identified in plasma indicates failure sites and predicts clinical prognosis in non-small cell lung cancer progression during first-generation tyrosine kinase inhibitor therapy: a prospective observational study. Cancer Commun (Lond) 38:28. https:// doi.org/10.1186/s40880-018-0303-2 
Zill OA et al (2015) Cell-free DNA next-generation sequencing in pancreatobiliary carcinomas. Cancer Discov 5:1040-1048. https:// doi.org/10.1158/2159-8290.CD-15-0274

Publisher's Note Springer Nature remains neutral with regard to jurisdictional claims in published maps and institutional affiliations. 